\title{
Recomendaciones para el estudio y manejo farmacológico en pacientes adultos con sospecha de infección por SARS-CoV-2 (COVID-19)
}

Documento conjunto de Sociedad Chilena de Infectología, Sociedad Chilena de Medicina Intensiva y Sociedad Chilena de Enfermedades Respiratorias. Octubre 2020

Recommendations for the study and pharmacological management in adult patients with suspected infection by SARS-CoV-2 (COVID-19)
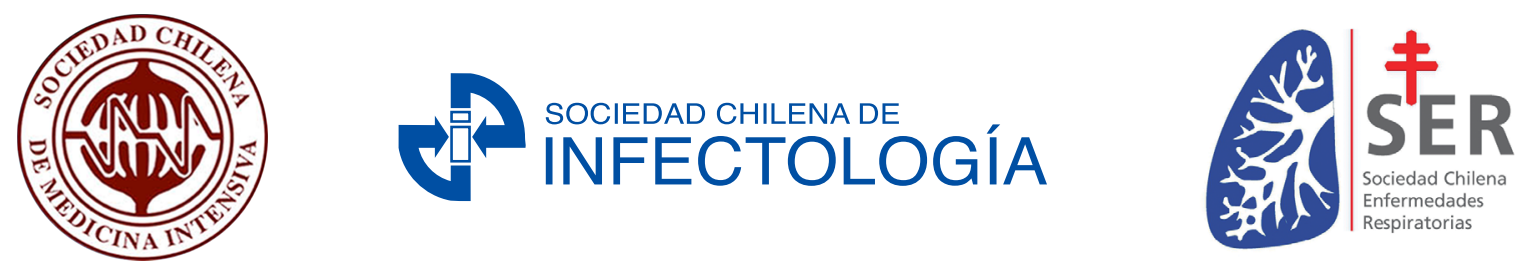

Elaborado por:

- Comité de Antimicrobianos Sociedad Chilena de Infectología (SOCHINF): Dr. Jorge Pérez, QF. Ruth Rosales, QF. Fernando Bernal, Dr. José Miguel Arancibia, Dra. Daniela Pavez, QF. Claudio González, Dra. Luz María Fuenzalida, Dra. Regina Pérez, Dra. Mirta Acuña, Dra. María Eugenia Pinto.

- Sociedad Chilena de Medicina intensiva (SOCHIMI): Dra. Cecilia Luengo, Dr. Tomás Regueira, QF. Mariana Arias, QF. Paula Impellizzeri, QF. Cristian Paredes, QF. Rubén Hernández.

- Sociedad Chilena de Enfermedades Respiratorias: Dr. Francisco Arancibia, Dr. Raúl Riquelme.

- Colaborador: Dr. Leonardo Chanqueo.

Un documento similar referido a esta patología en niños se publica en forma paralela.

Estas recomendaciones pueden variar según evolucione nuestro conocimiento acerca de la enfermedad y la situación epidemiológica.

La evidencia actual es limitada y sujeta a cambios y actualizaciones.

Introducción

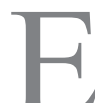

131 de diciembre de 2019, las autoridades de la ciudad de Wuhan en la provincia de Hubei, China, reportaron 27 casos de síndrome respiratorio agudo de etiología desconocida. El 7 de enero de 2020, las autoridades chinas informaron la identificación de un nuevo coronavirus, denominado "Coronavirus 2 del Síndrome Respiratorio Agudo Severo (SARS-CoV-2)", como agente etiológico de este síndrome ${ }^{1}$. El 3 de marzo se diagnosticó el primer caso de infección por virus SARS-CoV-2 en Chile. El 11 de marzo, la Organización Mundial de la Salud (OMS) declaró la infección por SARS-CoV-2, denominada "COVID-19", una pandemia, la cual se ha convertido en una emergencia sanitaria mundial.
La COVID-19 produce un cuadro respiratorio que se manifiesta en $80 \%$ de los casos como una infección respiratoria alta leve ${ }^{2}$. Sin embargo, en $20 \%$ puede producir una neumonía con distintos grados de hipoxemia que requiere hospitalización o bien, descompensación de una patología crónica del paciente infectado que también deba hospitalizarse. De este grupo, 5 a 16\% requerirá ingresar a una Unidad de Cuidados Intensivos (UCI), principalmente por hipoxemia grave, con necesidad de ventilación mecánica invasiva (VMI). Si bien se ha estimado la letalidad global de la COVID-19 entre 2 y $7 \%$, dependiendo de los factores de riesgo de la población y la capacidad de respuesta del sistema sanitario, la mortalidad en los pacientes que requieren VMI puede sobrepasar el $60 \%$.

La emergencia y excepcionalidad de esta situación conllevan que, 
actualmente, no exista medicamento específico alguno, aprobado para el tratamiento de COVID-19, basando su manejo en medidas de soporte precoz. No obstante, la elevada letalidad de los casos más graves ha llevado a buscar alternativas potenciales de tratamiento en fármacos con otras indicaciones. Hasta la fecha, se han publicado varios reportes de casos y protocolos de manejo farmacológico de países europeos y asiáticos que ya han sido afectados por esta pandemia, y últimamente, están apareciendo los reportes preliminares de estudios aleatorizados utilizando algunos de estos fármacos en pacientes en diferentes etapas evolutivas y con distintos niveles de gravedad de la enfermedad.

Dado que la administración de estos fármacos a pacientes con COVID-19 constituye un uso "fuera de indicación", los profesionales de las Sociedades Chilenas de Infectología (SOCHINF), Medicina Intensiva (SOCHIMI) y Enfermedades Respiratorias (SER), creemos que es importante analizar cuidadosamente la evidencia publicada respecto de dichos fármacos y el balance riesgo-beneficio durante su utilización, para ofrecer a quienes manejan este tipo de pacientes una recomendación que sea potencialmente beneficiosa, cuyos riesgos sean mínimos y que sea factible de aplicar en la mayor parte de los centros asistenciales de nuestro país.

\section{Métodos diagnósticos de infección por SARS-CoV-2 3-19}

Ver Tabla 1.

\section{Criterios de hospitalización, estudio y manejo general inicial}

\section{Criterios de hospitalización}

- Paciente con COVID-19 y reagudización de alguna co-morbilidad, con o sin neumonía.

- Paciente con neumonía y requerimientos de oxígeno:

- Se pueden utilizar criterios CURB-65 (mayor a 2) para decidir hospitalización (Anexo 1).

- Sala básica: En caso de estabilidad clínica y requerimientos de oxígeno hasta $4 \mathrm{lt} / \mathrm{min}$.

- Unidad de Cuidados Intermedios: Altos requerimientos de oxígeno, necesidad de soporte ventilatorio.

- Unidad de Cuidados Intensivos: Necesidad de VMI y/o con inestabilidad hemodinámica.

- También puede utilizarse para evaluar la gravedad al ingreso, los criterios de neumonía adquirida en la comunidad (NAC) según Infectious Disease Society of America/American Thoracic Society (IDSA/ATS) (Anexo 2).
- Se sugiere considerar la hospitalización en pacientes con neumonía al momento de la evaluación, que se sospeche puedan agravarse, porque presenten factores de riesgo tales como edad $>65$ años y/o co-morbilidad relevante (patología cardiovascular, diabetes mellitus, enfermedad respiratoria crónica, inmunosupresión) (Tabla 2).

\section{Estudio inicial de pacientes COVID-19 que} cumplen criterios de hospitalización ${ }^{21,22}$

- Panel viral respiratorio completo o acortado (influenza A/B y VRS), si la situación epidemiológica lo amerita.

- Hemocultivos periféricos (2) en caso de sospecha de sobreinfección bacteriana.

- Gases arteriales, electrolitos plasmáticos, hemograma, proteína $\mathrm{C}$ reactiva (PCR), $\mathrm{LDH}$, pruebas hepáticas, glicemia, creatinina, CK total, dímero D (DD). En caso de tener disponible: ferritina, fibrinógeno y troponina.

- Radiografía de tórax PA/lateral.

- TC tórax: Si la radiografía es normal, y existe alta sospecha diagnóstica, se recomienda realizar TC de tórax de estar disponible. Priorizar la TC de tórax en pacientes hospitalizados o sintomáticos con factores de riesgo. En pacientes que ingresan a la unidad de paciente crítico se recomienda realizar TC de tórax.

- Estudiar otras etiologías de infección respiratoria: antígenos urinarios para Streptococcus pneumoniae y Legionella pneumophila (neumonía grave) de estar disponibles, si el paciente se encuentra en Unidad de Cuidados intensivos o con sospecha de sobreinfección bacteriana.

- Baciloscopias (2) y cultivo para micobacterias según expresión clínica.

- Serología para VIH.

- Ante un cuadro clínico muy sugerente de COVID-19 con reacción de polimerasa en cadena (RPC) inicial negativa, ésta debe repetirse para aumentar su sensibilidad, idealmente de tracto respiratorio inferior.

- Considerar serología en paciente con alta sospecha clínica, RPC negativa y sintomático por más de 10 días.

\section{Manejo inicial de pacientes hospitalizados}

- Precauciones para el manejo de los pacientes: precauciones estándar (higiene de manos) + precaución de contacto (delantal manga larga y guantes) + precaución de gotitas (mascarilla quirúrgica) y uso de antiparras o escudos faciales.

Frente a procedimientos productores de aerosoles: kinesioterapia, intubación, ventilación con bolsa y mascarilla autoinflable, reanimación cardiopulmonar, ventilación mecánica no invasiva, traqueostomía, broncoscopia, aspiración abierta de vía aérea, cambiar la mascarilla quirúrgica por una N95 o equivalente. 
Tabla 1. Métodos diagnósticos

\begin{tabular}{|c|c|c|}
\hline & Amplificación de ácidos nucleicos & Detección de anticuerpos \\
\hline Tipo de muestra & $\begin{array}{l}\text { Tracto respiratorio superior: } \\
\text { - Hisopado nasofaríngeo y orofaríngeo } \\
\text { - Hisopado nasofaríngeo } \\
\text { - Hisopado orofaríngeo } \\
\text { - Hisopado nasal } \\
\text { Tracto respiratorio inferior: } \\
\text { (Ideal en IRA grave por mayor sensibilidad, pero presenta } \\
\text { mayor riesgo de generar aerosoles) } \\
\text { - Esputo no inducido } \\
\text { - Aspirado endotraqueal } \\
\text { - Lavado broncoalveolar }\end{array}$ & $\begin{array}{l}\text { - Sangre total (venopunción) } \\
\text { - Sangre capilar (punción digital) } \\
\text { - Suero o plasma }\end{array}$ \\
\hline Métodos disponibles & rRT-PCR, rRT-PCR POCT, RT-LAMP, CRISPR & ELISA, Quimioluminiscencia, Inmunocromatografía (ICG) \\
\hline $\begin{array}{l}\text { Positividad según } \\
\text { días de evolución y } \\
\text { severidad (valores muy } \\
\text { variables según estudios }\end{array}$ & $\begin{array}{l}\text { - Peak de positividad: 5-6 días desde iniciado los síntomas } \\
\text { - Se negativiza a partir del día } 8 \text { de iniciado los síntomas } \\
\text { - Desde el día } 8 \text { al } 22 \text { sería positiva en muestras de esputo o } \\
\text { heces }\end{array}$ & $\begin{array}{l}\text { Mediana de seroconversión: } \\
\text { - IgM: día 10-12 } \\
\text { - IgG: día 12-14 }\end{array}$ \\
\hline
\end{tabular}

La detección de Ac después de la $1^{\text {ra }}$ semana es de sólo un 30\%, 70\% durante la $2^{\text {da }}$ y más de $90 \%$ en la $3^{\text {ra }}$ semana.
Utilidad
- Técnica de referencia y de elección para el diagnóstico de COVID-19
- Como estudio complementario en pacientes sospechosos con PCR negativa, presentación tardía o complicación secundaria (Ej. PIMS) o pacientes sin PCR realizados. Ideal 2 a 3 semanas después del inicio de síntomas.

- Estudios epidemiológicos de prevalencia poblacional o comunitarios.

- Estudios de prevalencia puntual como personal de salud, adultos mayores o embarazadas.

- Detección de pacientes expuestos al virus y posibles donantes de suero hiperinmune.

- Evaluación de vacunas.

Limitaciones de la serología SARS-CoV-2:

- Pueden existir falsos positivos por reactividad cruzada con otros coronavirus.

- Se desconoce si una serología positiva otorga inmunidad o protección contra una reinfección.

- No está claro cuánto tiempo permanecen detectables los anticuerpos lgM e lgG en el tiempo.

- Algunas personas no desarrollan anticuerpos detectables después de la infección por COVID-19.

- La interpretación debe ser realizada en base a la clínica, epidemiología, prevalencia de la enfermedad, S, E y VPP.

S: Sensibilidad; E: especificidad; VPP: valor predictivo positivo. rRT-PCR: reacción en cadena de la polimerasa con transcriptasa inversa en tiempo real; POCT: point of care testing; RT-LAMP: reverse transcription loop-mediated isothermal amplification; CRISPR: clustered regularly interspaced short palindromic repeats; PIMS: Síndrome inflamatorio multisistémico. 


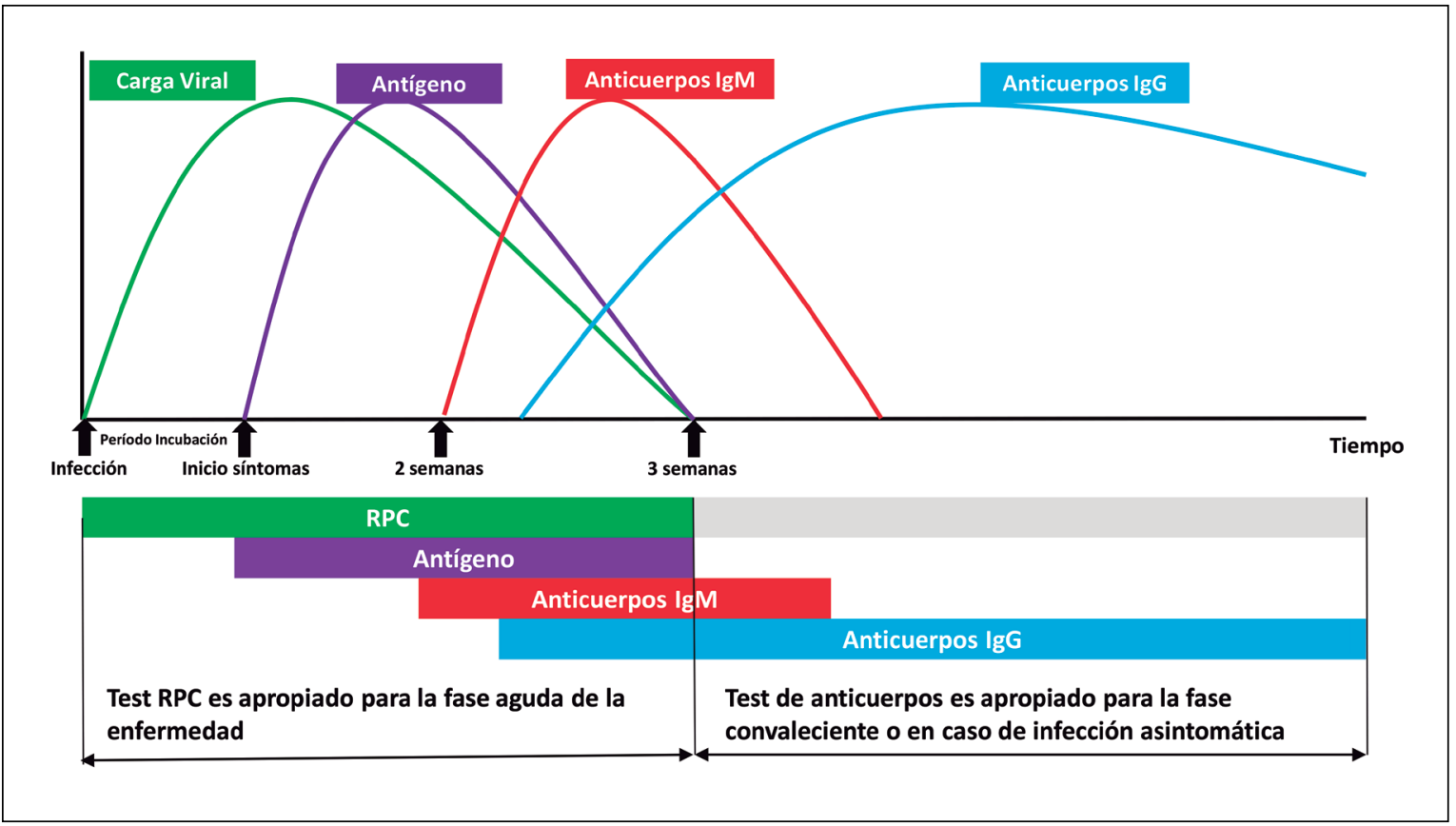

Figura 1. Métodos diagnósticos para SARS CoV2 (adaptada de "Interpreting Diagnostic Tests for SARSCoV-2"20.

\begin{tabular}{|c|c|c|}
\hline Epidemiología & Clínica & Laboratorio \\
\hline Edad $>65$ años & $\begin{array}{l}\text { Frecuencia respiratoria (FR) }>30 \text { (CURB-65) (anexo 1) } \\
\text { FR }>25 \text { en }<50 \text { años o }>30 \text { en }>50 \text { años. (SMART-COP) }\end{array}$ & Dímero D > $1.000 \mathrm{ng} / \mathrm{ml}$ \\
\hline Enfermedad pulmonar & Frecuencia cardíaca $>125$ lpm & Proteína C reactiva $>100 \mathrm{mg} / \mathrm{L}$ \\
\hline Enfermedad renal crónica & SatO $_{2}<90 \%$ con $\mathrm{O}_{2}$ ambiental en $>50$ años o $<93 \%$ en $<50$ años & $\mathrm{LDH}>245 \mathrm{U} / \mathrm{L}$ \\
\hline Diabetes mellitus & Confusión & Troponina elevada \\
\hline HTA & Mala perfusión distal & Linfopenia \\
\hline \multirow[t]{2}{*}{ Enfermedad cardiovascular } & CURB - $65 \geq 2$ (anexo 1) & Creatinina kinasa $>2$ veces valor de referencia \\
\hline & Obesidad IMC $\geq 30$ & Ferritina $>300 \mathrm{ug} / \mathrm{L}$ \\
\hline Transplantado o inmunosuprimido & & $\begin{array}{l}\text { Imagen de neumonía multifocal o presencia de } \\
\text { derrame pleural }\end{array}$ \\
\hline
\end{tabular}

- Se debe ajustar a protocolo de IAAS de cada institución.

- Oxígeno según requerimientos.

- En caso de neumonía:

- Ante sospecha de sobreinfección bacteriana, iniciar tratamiento antimicrobiano empírico para NAC según corresponda. Si ésta se descarta, suspender el tratamiento precozmente para evitar la inducción de resistencia.

- Iniciar oseltamivir si la vigilancia de virus respiratorio muestra aumento de circulación de virus influenza:
- $75 \mathrm{mg}$ c/12 h, en pacientes con aclaramiento de creatinina $\geq 60 \mathrm{ml} / \mathrm{min}$ por 5 a 10 días.

- $30 \mathrm{mg} \mathrm{c} / 12 \mathrm{~h}$ en aclaramiento de creatinina $\geq 30$ $\mathrm{y}<60 \mathrm{ml} / \mathrm{min}$.

- $30 \mathrm{mg} \mathrm{c} / 24 \mathrm{~h}$, en aclaramiento de creatinina $<30$ $\mathrm{y} \geq 10 \mathrm{ml} / \mathrm{min}$.

- En pacientes en hemodiálisis trisemanal: $30 \mathrm{mg}$ los días de diálisis post procedimiento.

- Suspender si el test de influenza es (-).

- No utilizar nebulizaciones, sólo inhaladores de dosis fija con cámara espaciadora. 
- No suspender la terapia corticosteroidal ni inhaladores con corticosteroides en pacientes que tienen indicación por patología crónica.

- No cambiar o suspender antihipertensivos ARA 20 IECA si el paciente es usuario.

- En pacientes con requerimiento de $\mathrm{O}_{2} \mathrm{y}$ uso de musculatura accesoria, se recomienda intentar estrategia de prono vigil, y cánula nasal de alto flujo (CNAF) + mascarilla quirúrgica. Esto permite manejar adecuadamente a un porcentaje de pacientes con hipoxemia, evitando llegar a la VMI o bien, dar un manejo apropiado a pacientes en que se define como desproporcionada la VMI.

\section{Recomendaciones para el tratamiento farmacológico pacientes con COVID-19}

Ver algoritmo de manejo (Figura 2) $22-30$.

\section{Ambulatorios}

Sin neumonía o neumonía sin necesidad de oxigenoterapia:

- Manejo sintomático.

- Recomendamos NO indicar tratamiento específico en forma ambulatoria.

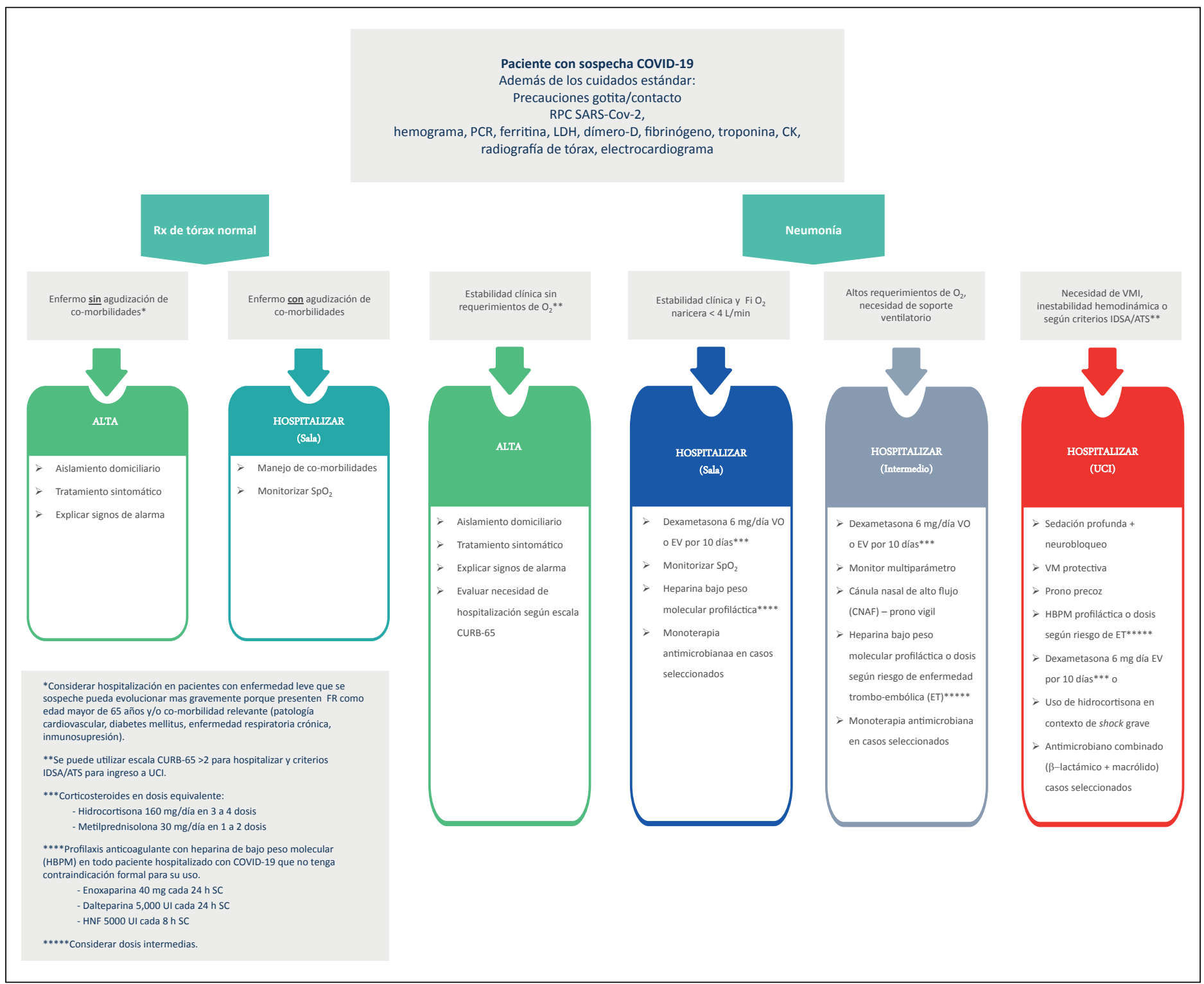

Figura 2. Algoritmo de manejo pacientes adultos con COVID-19. 
aleatorizado, doble ciego placebo-controlado, que incluyó 647 pacientes, utilizando $0,5 \mathrm{mg} / \mathrm{kg}$ de metilprednisolona 2 veces al día durante 5 días en pacientes hospitalizados con sospecha/confirmación de COVID-19, donde no se observó una reducción en la mortalidad a 28 días. No obstante, en los datos suplementarios del meta-análisis, se realizó esta consideración, y se reajustó el OR a 0,8 IC95\% $[0 .-1,63] \mathrm{p}=0,5$, sin perjudicar los datos finales publicados, más sólo reduciendo la inconsistencia.

Dado que no existe otro medicamento que haya mostrado beneficios relacionados a la sobrevida de los pacientes con COVID-19, que es un medicamento de bajo precio, altamente disponible, y que las dosis probadas son relativamente bajas, se sugiere el uso de dexametasona 6 mg/día en pacientes hospitalizados con COVID-19 que requieran oxígeno o se encuentren en VMI, y en quienes se haya descartado sobreinfección y/o trombo-embolismo pulmonar (TEP) como causa de estos requerimientos. No se recomienda el uso de corticosteroides en aquellos pacientes sin insuficiencia respiratoria.

Equivalencia de dosis glucocorticoides:

- Hidrocortisona $150 \mathrm{mg}$ al día, administrado en 3 dosis.

- Metilprednisolona $30 \mathrm{mg}$ al día, administrado en $1 \mathrm{o}$ 2 dosis.

En concordancia a nuestras recomendaciones, la OMS sugiere el uso de corticosteroides en pacientes con enfermedad grave, con un fuerte nivel de recomendación, pero no así en pacientes con enfermedad no grave, principalmente debido al bajo nivel de certeza de los estudios disponibles ${ }^{35}$.

\section{Anticoagulación}

Diferentes reportes y estudios clínicos de China, Europa y más tarde Estados Unidos de América, han mostrado una importante incidencia de complicaciones trombóticas y trombo-embólicas, principalmente venosas, pero también arteriales, en pacientes con COVID-19 $9^{36-38}$. Estas complicaciones reflejarían un estado protrombótico, producto de injuria o disfunción endotelial producida por el SARS-CoV-2, que se manifiesta en el laboratorio con aumento importante de DD, fibrinolisis, y disminución del recuento de plaquetas, y en la clínica con microtrombosis de pequeños vasos, embolia pulmonar, y trombosis venosas en extremidades, entre otras ${ }^{39}$. Estas complicaciones parecen, a su vez, ser más frecuentes en los pacientes más graves y se asocian a peores desenlaces.

Estos hallazgos enfatizan la importancia de la profilaxis anticoagulante en pacientes con COVID-19. En un estudio en pacientes en ventilación mecánica ${ }^{40}$, la administración de profilaxis anticoagulante se asoció con menor mortalidad hospitalaria en comparación con pacientes que no la recibieron $(29,1$ y $62,7 \%$, respectivamente). 
Sin embargo, cuando se consideran todos los pacientes hospitalizados, incluidos aquéllos que no requirieron ventilación mecánica, no se encontró diferencia en la mortalidad intrahospitalaria. Otro estudio retrospectivo de 499 pacientes con COVID-19 grave ${ }^{41}$, mostró una diferencia significativa en la mortalidad de pacientes con DD elevado ( $>6$ veces valor normal) que recibieron heparina de bajo peso molecular (HBPM) en comparación con aquéllos que no la recibieron ( 32,8 y 52,4\%, respectivamente).

En este contexto, la International Society of Thrombosis and Haemostasis (ISTH) ${ }^{42}$ ha propuesto una categorización que identificaría pacientes con una "coagulopatía inducida por sepsis" (SIC). Los pacientes con puntaje SIC $\geq 4$, o con DD notablemente elevado, se beneficiarían de tratamiento anticoagulante. Sin embargo, no existe evidencia suficiente para respaldar un tratamiento anticoagulante basado sólo en este puntaje o en un valor umbral de DD, el que no está uniformemente establecido.

- Profilaxis anticoagulante farmacológica en TODO paciente hospitalizado con COVID-19 que no tenga contraindicación formal para su uso. Si existe contraindicación, debe implementarse profilaxis mecánica mediante compresión neumática intermitente.

- Utilizar heparinas de bajo peso molecular (HBPM) en pacientes con aclaramiento de creatinina estimado $\geq 30$ $\mathrm{ml} / \mathrm{min}$, mientras que en aquéllos con aclaramiento de creatinina estimado $<30 \mathrm{~mL} / \mathrm{min}$, se recomienda profilaxis anticoagulante con heparina convencional. También se recomienda heparina no fraccionada (HNF) en pacientes con peso $>150 \mathrm{~kg}$ o IMC mayor a 40.

- Dosis estándares: enoxaparina $40 \mathrm{mg} /$ día sc, dalteparina 5.000 U/día sc o HNF $5.000 \mathrm{UI} \mathrm{c/8} \mathrm{h} \mathrm{sbc.}$

- Medir DD al ingreso y en forma seriada para estratificar el riesgo potencial y considerar la toma de imágenes.

a. En pacientes con $\mathrm{DD}<1.000 \mu \mathrm{g} / \mathrm{L}$ al ingreso y sin aumento significativo en seguimiento, debe mantenerse profilaxis con HBPM.

b. En pacientes con $\mathrm{DD}<1.000 \mu \mathrm{g} / \mathrm{L}$ al ingreso, pero que aumenta significativamente durante la hospitalización ( $>2.000-4.000 \mu \mathrm{g} / \mathrm{L})$, considerar imágenes en busca de trombosis venosa profunda (TVP) y/o TEP, especialmente si hay deterioro clínico o aparecen signos sugerentes de congestión venosa o hipercoagulabilidad.

c. En pacientes con DD elevado al ingreso (2.000$4.000 \mu \mathrm{g} / \mathrm{L}$ ), se recomienda repetir a diario y considerar imágenes para detectar o descartar TVP y/o TEP.

- Actualmente, no existe evidencia que apoye el uso de dosis mayores de tromboprofilaxis, en pacientes con COVID-19. Por lo tanto, se sugiere una evaluación individualizada, teniendo en consideración el riesgo de trombosis y sangrado de cada paciente. Algunos factores a considerar son: $\mathrm{PaFi}<300 \mathrm{mmHg}$, puntaje $\mathrm{SIC} \geq 4$, DD elevado y alto requerimiento de oxígeno.

- En pacientes con riesgo intermedio-alto, considerar dosis de enoxaparina $0,5 \mathrm{mg} / \mathrm{kg} \mathrm{c} / 12 \mathrm{~h}$ o dosis equivalentes de dalteparina subcutánea.

- Mantener un nivel alto de sospecha de complicación tromboembólica, y realizar pruebas diagnósticas adecuadas (AngioTC de tórax) frente a signos de descompensación del paciente, tales como: deterioro repentino de la oxigenación, disminución súbita de la presión arterial, taquicardia de inicio súbito y persistente sin etiología clara, hemoptisis, sobrecarga ventricular derecha, cambios en el ECG sugerentes de TEP, o síntomas /signos de TVP tales como aumento de volumen, temperatura y/o coloración de extremidades, etc.

- Si bien el uso de dosis terapéuticas de anticoagulación como prevención primaria no está recomendada, considere el inicio de anticoagulación en pacientes con alta sospecha clínica de complicación tromboembólica (taquicardia o deterioro gasométrico sin causa aparente), en quienes su nivel de inestabilidad impida realizar diagnóstico por imágenes.

- En caso de tener disponible, considere monitorizar la anticoagulación con niveles de anti-Xa, en pacientes con pesos extremos $(<50 \mathrm{~kg}$ o $>$ de $100 \mathrm{~kg})$, y/o disfunción renal aguda que no contraindique el uso de HBPM. La toma de muestra para factor anti-Xa se debe realizar 4 a $6 \mathrm{~h}$ posteriores a la administración de la HPBM y el valor objetivo para anticoagulación es de $0,5-1 \mathrm{U} / \mathrm{ml}$ para dosificación cada 12 h y $1-1,5$ $\mathrm{U} / \mathrm{ml}$ para dosificación cada $24 \mathrm{~h}$. Los valores para tromboprofilaxis son $0,1-0,25 \mathrm{U} / \mathrm{ml}$.

- No hay estudios que evalúen la tromboprofilaxis extendida en pacientes con COVID-19. Sin embargo, dada la elevada incidencia de trombosis, frecuente necesidad de UCI, intubación, sedación y ventilación prolongadas, lo que implica des-acondicionamiento y movilidad reducida al alta, se recomienda considerar tromboprofilaxis extendida en pacientes con bajo riesgo de sangrado y factores de riesgo, tanto basales como asociados a la neumonía por SARS-CoV-2 (edad avanzada, cáncer, trombo-embolismo venoso previa, trombofilia, inmovilidad extrema, DD $>2$ veces el valor normal; estadía en UCI, VMI), de acuerdo a algún score como el IMPROVE Bleed (IMPROVE score mayor o igual a 4 puntos) (Tabla 3 ). En este caso, se recomienda el uso de HBPM o anticoagulante de acción directa (DOACs) por un período mínimo de 2 semanas y hasta por 6 semanas en las siguientes dosis:

- Rivaroxabán en dosis de 10 mg al día.

- Enoxaparina en dosis de $40 \mathrm{mg}$ al día.

Este tratamiento dependerá de la presencia de factores pro-trombóticos persistentes, debe decidirse caso a caso, y bajo control médico estricto (Tabla 4). 
Tabla 3. Criterios Neumonía grave IDSA/ATS

\section{Criterios mayores}

- Insuficiencia respiratoria con necesidad de ventilación mecánica

- Shock séptico con necesidad de vasopresores

Es un análogo de nucleótido en investigación con un espectro antiviral amplio. In vitro inhibe todos los coronavirus animales y humanos, incluyendo SARS-CoV-2, $\mathrm{y}$ en animales tiene actividad in vivo contra patógenos como MERS-CoV y SARS-CoV-1. Remdesivir recibió la autorización de uso de emergencia por la FDA en mayo 2020, basado en la información de dos ensayos clínicos aleatorizados que compararon el uso de remdesivir por 10 días versus placebo (Wang y cols. ${ }^{47}$, y ACTT- $1^{48}$ ). El primer estudio, no demostró beneficio, reclutando sólo a 237 pacientes de la población estimada en su diseño, siendo un estudio de poca potencia ${ }^{47}$. El segundo estudio $^{48}$ asignó al azar a 1.063 pacientes y encontró que aquellos que recibieron 10 días de remdesivir tuvieron un tiempo de recuperación 4 días más corto, 11 días para remdesivir vs 15 días en comparación al placebo, sin demostrar beneficios en mortalidad a 14 días. Los datos finales de mortalidad a 29 días fueron publicados en octubre del 2020 estimándose una mortalidad de 11,4 vs $15,2 \%$ para remdesivir versus placebo, respectivamente, con un hazard ratio 0,73 (IC 95\% 0,52-1,03). Un tercer ensayo clínico aleatorizado (ECA), doble ciego, publicado recientemente por Spinner y cols. ${ }^{49}$, reclutó a 584 pacientes que fueron aleatorizados 1:1:1 a remdesivir por 10 días $(\mathrm{n}=193)$ o 5 días $(\mathrm{n}=191)$ o un grupo control con atención estándar $(n=200)$. El criterio de valoración primario original fue la proporción de pacientes dados de alta al día 14, pero el criterio de valoración se cambió al inicio del estudio a una escala ordinal de 7 puntos de estado clínico (rango: muerte $=1$ a alta $=7$ ) evaluados el día 11 del estudio. Los outcomes secundarios incluyeron el tiempo hasta la recuperación, el tiempo hasta la mejoría clínica, la duración de la estancia hospitalaria, los eventos adversos y la mortalidad. El estudio de Spinner y cols., informó beneficio con un tratamiento de 5 días, pero, al igual que el estudio de Wang y cols., no informó beneficio alguno con la rama de 10 días que había demostrado ser beneficioso en ACTT-1. Por lo tanto, existen tres ECA en pacientes hospitalizados con diferentes resultados, lo que plantea un cuestionamiento respecto a si estas discrepancias son resultado del diseño de los estudios, incluidas las poblaciones de pacientes, o si en realidad, el fármaco es menos eficaz de lo esperado.

Es plausible que la terapia antiviral sea más eficaz si se inicia precozmente y, por lo tanto, su uso en pacientes con enfermedad moderada es un enfoque razonable. Sin embargo, la gravedad y la duración no son sinónimos: tanto en el estudio de Spinner y cols., como en el ACTT-1, los pacientes informaron una mediana de 9 días de síntomas antes del reclutamiento. El uso de un enfoque de escala

\section{Criterios menores}

- Frecuencia respiratoria $\geq 30$ respiraciones/min

- $\mathrm{PaO}_{2} / \mathrm{FlO}_{2} \leq 250$

- Infiltrado multilobar

- Confusión/desorientación

- Uremia $\geq 20 \mathrm{mg} / \mathrm{dl}$

- Leucopenia $\leq 4.000$ células/ $\mu$ l

- Trombocitopenia (recuento de plaquetas $<100.000 / \mu \mathrm{l}$ )

- Hipotermia

- Hipotensión que requiera resucitación con fluidos enérgica

Neumonía grave: 1 criterio mayor o 3 o más criterios menores

\begin{tabular}{|ll|}
\hline $\begin{array}{l}\text { Tabla 4. IMPROVE SCORE para riesgo de } \\
\text { tromboembolismo venoso }\end{array}$ \\
\hline Tromboembolismo venoso previo \\
Trombofilia conocida & 3 \\
\hline Parálisis extremidades inferiores & 2 \\
Cáncer activo & 2 \\
Inmovilización > a 7 días & 2 \\
Estadía en UCl & 1 \\
Edad $>60$ años & 1 \\
\hline Nivel de riesgo: & 1 \\
Score de 0 a 1 bajo riesgo & \\
Score 2 a 3 moderado riesgo & \\
Score $\geq 4$ alto riesgo & \\
\hline
\end{tabular}

ordinal está respaldado por la Organización Mundial de la Salud y es común en los ECA de COVID-19. Sin embargo, esta escala es un outcome recién creado y aún en validación. Por otra parte, aunque algunos pacientes en los diferentes estudios recibieron corticosteroides, no hubo una aleatorización cruzada formal. Spinner y cols. entregan información sobre la potencial eficacia de remdesivir en pacientes con COVID-19 moderado y sugieren un beneficio clínico modesto con un tratamiento de 5 días en comparación con el cuidado estándar, aunque, la importancia clínica de este hallazgo es incierta. Es necesario considerar que el perfil de efectos adversos en los ECA ha llevado a un alto porcentaje de interrupciones de tratamiento $(12 \%)^{47}$, y eventos adversos graves grado 3 o 4 en 21 a $28 \%$ en la rama de remdesivir ${ }^{47,48}$. Tanto la población objetivo, la duración óptima del tratamiento, como el efecto sobre los resultados clínicos modestos aún no quedan claros. Por último, es importante disponer de nuevos ECA que valoren el efecto relativo de remdesivir cuando se administra en presencia de dexametasona $u$ otros corticosteroides (Tabla 5). 
Tabla 5. Estudios clínicos de remdesivir

Resumen evidencia in vitro o previa para el uso de remdesivir

Autor País Tipo Comentarios

Wang y cols. ${ }^{50} \quad$ China Actividad in-vitro Potente actividad contra SARS-CoV-2 con una CE ${ }_{50}$ a 48 h de $0,77 \mu \mathrm{M}$ en células Vero E6

Sheahan y cols. ${ }^{51} \quad$ E.U.A. Modelos animales Modelos animales infectados con MERS-CoV. Títulos virales en pulmón y score de lesión pulmonar. Mejor resultado con inicio precoz

Midgley y cols. ${ }^{52} \quad$ E.U.A. Reportes de casos Tres pacientes de origen americano con COVID-19 lo recibieron como uso compasivo con evolución adecuada, aunque sin una relación clara con el medicamento

Humeniuk y cols. ${ }^{53} \quad$ Miami, E.U.A. Voluntarios sanos

Se lograron altas concentraciones intracelulares del trifosfato activo (aproximadamente 220 a 370 veces más altas que la $\mathrm{CE}_{50}$ in vitro contra el aislado clínico de SARS-CoV-2) después de la infusión de formulación liofilizada de 75 mg o 150 mg durante 30 min o 2 h

CE: concentración efectiva

\begin{tabular}{|c|c|c|c|c|c|c|c|c|}
\hline Estudio & País/Hospital & Diseño & $\begin{array}{c}\# \\
\text { pacientes }\end{array}$ & Intervención & Control & Outcome & Resultado & $\begin{array}{l}\text { Valor p o RR o dife- } \\
\text { rencia porcentual }\end{array}$ \\
\hline \multirow[t]{2}{*}{ Goldman y cols. ${ }^{54}$} & \multirow[t]{2}{*}{ Multicéntrico } & \multirow[t]{2}{*}{$\begin{array}{l}\text { ECA, } \\
\text { abierto }\end{array}$} & \multirow[t]{2}{*}{397} & \multirow[t]{2}{*}{$\begin{array}{l}\text { Remdesivir } 5 \text { días } \\
\quad(n=200)\end{array}$} & \multirow[t]{2}{*}{$\begin{array}{l}\text { Remdesivir } \\
10 \text { días } \\
(n=197)\end{array}$} & $\begin{array}{l}\text { Estado clínico } \\
\text { día } 14\end{array}$ & $\begin{array}{l}\text { Sin diferencia con } \\
\text { curso de } 5 \text { o } 10 \text { días } \\
\text { de remdesivir }\end{array}$ & $p=0,14$ \\
\hline & & & & & & $\begin{array}{l}\text { Mejoría clínica } \\
\text { (mediana en } \\
\text { días) }\end{array}$ & 5d: 10 vs 10d: 11 & $\begin{array}{l}\text { Diferencia: } 0,79 \\
\text { (IC95\% 0,61-1,01) }\end{array}$ \\
\hline Wang y cols. ${ }^{47}$ & China & $\begin{array}{l}\mathrm{ECA}, \\
\text { doble } \\
\text { ciego }\end{array}$ & 237 & $\begin{array}{l}\text { Remdesivir } 200 \text { mg } \\
\text { día 1, luego } 100 \text { mg/ } \\
\text { día por } 9 \text { días } \\
(n=158)\end{array}$ & $\begin{array}{l}\text { Placebo } \\
(\mathrm{n}=79)\end{array}$ & $\begin{array}{l}\text { Tiempo mejoría } \\
\text { clínica (días) }\end{array}$ & $\begin{array}{c}21(13-28) \text { RDS vs } \\
\text { placebo } 23(15-28)\end{array}$ & $\begin{array}{c}\text { HR 1,23 } \\
\text { (IC95\%: 0,87-1,75) }\end{array}$ \\
\hline \multirow[t]{3}{*}{ Beigel y cols. ${ }^{48}$} & \multirow[t]{3}{*}{ Multicéntrico } & \multirow[t]{3}{*}{$\begin{array}{l}\text { ECA, } \\
\text { doble } \\
\text { ciego }\end{array}$} & \multirow[t]{3}{*}{1.062} & \multirow{3}{*}{$\begin{array}{l}\text { Remdesivir } 200 \text { mg } \\
\text { día 1, luego } 100 \text { mg/ } \\
\text { día por } 9 \text { días } \\
(\mathrm{n}=541)\end{array}$} & \multirow[t]{3}{*}{$\begin{array}{l}\text { Placebo } \\
(n=521)\end{array}$} & $\begin{array}{c}\text { Tiempo de recu- } \\
\text { peración }\end{array}$ & $\begin{array}{c}11 \text { días (IC95\% 9-12) } \\
\text { RDS vs } 15 \text { (IC95\% } \\
\text { 13-19) Placebo }\end{array}$ & $\begin{array}{c}\text { HR 1,.32 } \\
(\text { IC95\%: 1,12-1,55), } \\
p<0,001\end{array}$ \\
\hline & & & & & & $\begin{array}{l}\text { Mortalidad } 14 \\
\text { días }\end{array}$ & $\begin{array}{c}7,1 \% \text { RDS vs } 11,9 \% \\
\text { placebo }\end{array}$ & $\begin{array}{c}\text { HR 0,7 } \\
\text { (IC95\%: 0,47-1,04) }\end{array}$ \\
\hline & & & & & & Eventos adversos & $\begin{array}{c}21.1 \% \text { RDS vs } 27 \% \\
\text { placebo }\end{array}$ & $\mathrm{N} / \mathrm{D}$ \\
\hline \multirow[t]{2}{*}{ Grein y cols. ${ }^{55}$} & \multirow[t]{2}{*}{ Multicéntrico } & \multirow[t]{2}{*}{ Cohorte } & \multirow[t]{2}{*}{53} & \multirow{2}{*}{$\begin{array}{l}\text { Remdesivir } 200 \text { mg } \\
\text { día 1, luego } 100 \text { mg/ } \\
\text { día por } 9 \text { días } \\
(\mathrm{n}=53)\end{array}$} & \multirow[t]{2}{*}{$\begin{array}{l}\text { Sin grupo } \\
\text { control }\end{array}$} & $\begin{array}{l}\text { Mejoría clínica } \\
\text { ( } n^{\circ} \text { pacientes) }\end{array}$ & $\begin{array}{c}\text { 36/53 pacientes } \\
(68 \%)\end{array}$ & \multirow[t]{2}{*}{$\begin{array}{c}\text { Sin cálculos esta- } \\
\text { dísticos }\end{array}$} \\
\hline & & & & & & $\begin{array}{l}\text { Mortalidad } 14 \\
\text { días }\end{array}$ & $\begin{array}{c}\text { VMI } 18 \%, \text { No-VMI } \\
5 \%\end{array}$ & \\
\hline \multirow[t]{3}{*}{ Spinner y cols. ${ }^{49}$} & \multirow[t]{3}{*}{ Multicéntrico } & \multirow[t]{3}{*}{$\begin{array}{l}\text { ECA, } \\
\text { abierto }\end{array}$} & \multirow[t]{3}{*}{584} & $\begin{array}{l}\text { Remdesivir } 200 \mathrm{mg} \\
\text { día 1, luego } 100 \mathrm{mg} \\
\text { por } 4 \text { días } \\
(\mathrm{n}=191)\end{array}$ & \multirow[t]{3}{*}{$\begin{array}{l}\text { Cuidado } \\
\text { estándar } \\
(n=200)\end{array}$} & $\begin{array}{c}\text { Mejoría clínica al } \\
\text { día } 11\end{array}$ & $\begin{array}{l}\text { 5-días vs cuidado } \\
\text { estándar }\end{array}$ & $\begin{array}{c}\text { OR } 1,65(1,09-2,48) \\
p=0,02\end{array}$ \\
\hline & & & & \multirow{2}{*}{$\begin{array}{l}\text { Remdesivir } 200 \mathrm{mg} \\
\text { día 1, luego } 100 \mathrm{mg} \\
\text { por } 9 \text { días } \\
(\mathrm{n}=193)\end{array}$} & & & $\begin{array}{c}\text { 10-días vs cuidado } \\
\text { estándar }\end{array}$ & $p=0,018$ \\
\hline & & & & & & Efecto adverso & $\begin{array}{l}\text { 5-días } 51 \% \text { vs } 10 \text { - } \\
\text { días } 59 \% \text { vs } 47 \% \\
\text { cuidado estándar }\end{array}$ & $\mathrm{N} / \mathrm{A}$ \\
\hline
\end{tabular}

$\mathrm{ECA}=$ ensayo clínico aleatorizado; $\mathrm{HR}=$ hazard ratio; IC95\% = intervalo de confianza del 95\%; N/D = no determinado; OR = odd ratio; RDS = remdesivir; $\mathrm{VMI}=$ ventilación mecánica invasiva. 
Conclusión: Dada la evidencia actual disponible, se recomienda evaluar individualmente el potencial beneficio del uso de remdesivir -una vez se encuentre disponible- en pacientes con enfermedad grave o moderada, considerando, además, el eventual costo-beneficio de dicha intervención.

\section{Favipiravir}

Es un fármaco antiviral de administración oral, inhibidor in vitro de la ARN polimerasa de algunos virus ARN (influenza, hantavirus, norovirus y coronavirus ${ }^{56}$, aprobado en Japón el año 2014 para uso en influenza resistente a otros antivirales y actualmente ha sido autorizado por Rusia y otros países en pacientes COVID-19, debido a información de su actividad in vitro e in vivo.

Dentro de la información científica disponible destaca un estudio aleatorizado efectuado en China en 29 pacientes COVID-1957, el que no mostró beneficios en la reducción de la carga viral o en el tiempo desde la randomización a la mejoría clínica, comparado con baloxavir y contra tratamiento usual. Otro estudio aleatorizado en pacientes con neumonía por COVID-19 $(\mathrm{n}=236)^{58}$, logró mayor mejoría clínica a los 7 días que umifenovir (Arbidol) y hubo menor tiempo en resolución de tos y fiebre, aunque sólo en el subgrupo de neumonía moderada. En este estudio destacó un perfil de seguridad con elevación de enzimas hepáticas, síntomas psiquiátricos y afectación gastrointestinal igual en ambos grupos, mientras que en el grupo de favipiravir hubo elevación de ácido úrico de forma más frecuente. Datos preliminares de un estudio aleatorio ruso que probó dos esquemas de dosificación de favipiravir contra tratamiento usual ${ }^{59}$, mostró una mayor proporción de aclaramiento viral al $5^{\circ}$ y $10^{\circ}$ día, en comparación al tratamiento usual (aunque sólo significativo para el $5^{\circ}$ día), y una mediana de normalización de temperatura alta menor para el antiviral.

Existe discusión de si las dosis utilizadas en los estudios podrían ser insuficientes para lograr los objetivos farmacodinámicos en pacientes $\operatorname{críticos}^{60}$, proponiendo esquemas con dosis más altas a partir de modelaciones farmacocinéticas, aún sin evaluación ${ }^{61}$.

Además, por tratarse de un medicamento aún sometido a estudios clínicos en esta nueva indicación, recién se está conociendo su perfil de seguridad, y su capacidad de interactuar con otros medicamentos. También se ha observado elevación del ácido úrico y prolongación de $\left.\mathrm{QT}^{58,6}\right)$ y ya han reportado 2 casos de síndrome neuroléptico maligno ${ }^{63}$ (Tabla 6).

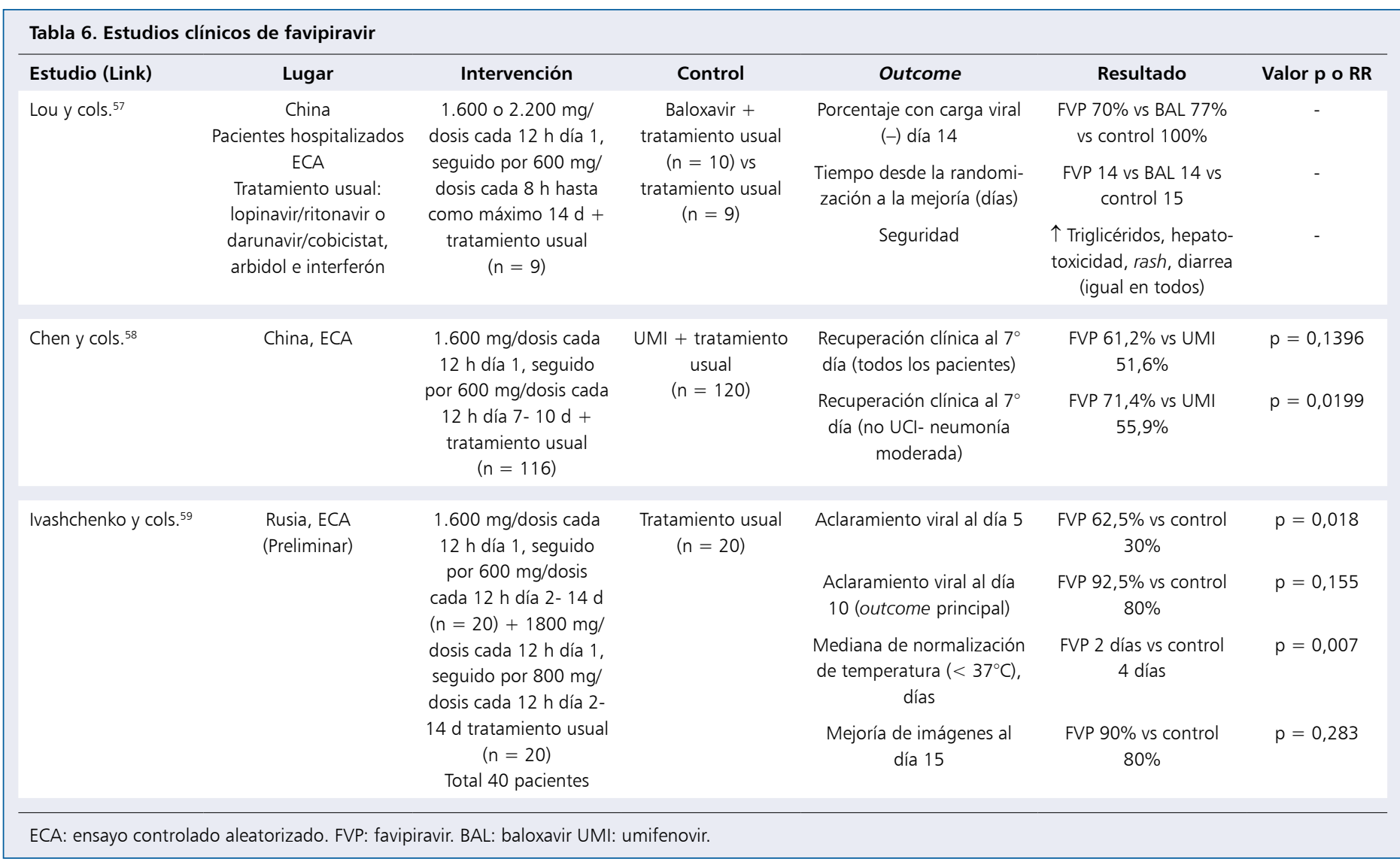


Conclusión: Por lo tanto, la evidencia actual, con pocos estudios publicados y bajo número de pacientes, no permite definir el valor de favipiravir en el tratamiento de pacientes con COVID-19, y no se recomienda por ahora su uso de rutina. Buena parte de los estudios están en desarrollo, pre publicación o corresponden a informes preliminares.

\section{Hidroxicloroquina}

Ha sido usada desde hace años como antimalárico y como antiinflamatorio en enfermedades autoinmunes, como lupus eritematoso diseminado y artritis reumatoidea. También es conocida su acción antiviral bloqueando la entrada de muchos virus a la célula, elevando el pH del endosoma, previniendo la fusión y evitando la replicación viral $^{64,65}$

Durante los primeros meses de la pandemia se evaluó el efecto de hidroxicloroquina mediante estudios observacionales y algunos ensayos clínicos aleatorizados de poco tamaño muestral ${ }^{66-68}$. Los outcomes fueron diversos, incluyendo mortalidad, progresión a ventilación mecánica, cambios radiológicos, cura virológica, estadía hospitalaria, entre otros. Muchos de estos trabajos, por todas las limitaciones metodológicas impuestas por sus diseños, no permitían establecer beneficio ni riesgo de esta intervención terapéutica, tanto en pacientes hospitalizados como en ambulatorios. Durante julio 2020 han aparecido los resultados de nuevos ensayos clínicos aleatorizados, todos con un tamaño muestral alto. Uno de ellos muestra que hidroxicloroquina como profilaxis post-exposición es igual a placebo en la prevención de la enfermedad ${ }^{69}$. Otro muestra que, en pacientes ambulatorios con síntomas leves, y duración de síntomas menor a 5 días, no es distinto al placebo en efecto sobre la carga viral, hospitalización o duración de los síntomas ${ }^{70}$. En el contexto de pacientes hospitalizados y terapias contra SARS-CoV-2 uno de los estudios más importantes ha sido RECOVERY (Randomised Evaluation of COVid-19 theERapY) que, entre varios medicamentos, evaluó hidroxicloroquina contra los cuidados estándar en mortalidad y tiempo de estadía hospitalaria, no encontrando diferencias para estos importantes outcomes ${ }^{71}$.

En la Tabla 7 se muestran los principales estudios existentes a la fecha:

Conclusión: Dada la evidencia actual, hidroxicloroquina NO debe ser usada como tratamiento ni prevención de la enfermedad producida por coronavirus SARS-CoV-2.

\section{Combinación hidroxicloroquina y azitromicina}

Con respecto al uso combinado de estos dos fármacos, estudios iniciales mostraban nulo efecto de esta asocia- ción $^{67,78-81}$ y en julio 2020 se publicó en la revista New England Journal of Medicine un ensayo clínico aleatorizado que ratificó este hallazgo ${ }^{82}$ (Tabla 8).

Adicionalmente, existen potenciales riesgos electrocardiográficos de la asociación, que han sido revisado por distintos grupos y que demuestran más riesgos que beneficios con esta asociación ${ }^{68}$.

Conclusión: Dada la evidencia actual, la combinación de hidroxicloroquina más azitromicina NO debe ser usada como tratamiento ni prevención de la enfermedad producida por coronavirus SARS-CoV-2.

\section{Lopinavir/ritonavir}

Los inhibidores de proteasa inhiben la replicación viral al actuar a nivel de la proteinasa mayor del coronavirus. Ensayos en animales y humanos han demostrado su efectividad en SARS-CoV-1 y MERS-CoV ${ }^{83,84}$.

En un estudio aleatorizado en pacientes con neumonía grave por SARS-CoV-2 publicado en el New England Journal of Medicie, el uso de lopinavir/ritonavir asociado a tratamiento de soporte, no se asoció a mejoría clínica o a disminución de mortalidad en pacientes gravemente enfermos ${ }^{85}$. Posteriormente, el estudio RECOVERY replicó estos hallazgos ${ }^{86}$ (Tabla 9).

Conclusión: Dada la evidencia actual, lopinavir/ritonavir NO debe ser usada como tratamiento ni prevención de la enfermedad producida por coronavirus SARS-CoV-2.

\section{Interferón}

Sin evidencia actual de efectividad en pacientes con COVID- $19^{24}$

\section{Ivermectina}

Antiparasitario con potente actividad in vitro contra SARS-CoV- $2^{87}$, aunque se ha estimado farmacocinéticamente que las concentraciones necesarias para esta actividad implican dosis excesivamente altas en humanos $^{88}$. Un estudio no aleatorizado ${ }^{89}$ comparó la adición de ivermectina a hidroxicloroquina y azitromicina versus $\mathrm{HCQ} / \mathrm{AZT}$, mostró una menor longitud de hospitalización en el grupo con ivermectina (7,62 versus 13,22 días; $\mathrm{p}<0,001)$. En otro estudio observacional de 173 pacientes hospitalizados con ivermectina y 107 controles (Estudio ICON: Ivermectin in COvid Nineteen $)^{90}$ se observó una mortalidad significativamente más baja en el grupo con el antiparasitario (25\% versus $15,0 \%$, respectivamente OR 0,52, 95\% CI 0,29-0,96), asociación que se mantuvo ajustando por algunas co-variables, siendo más alto su efecto en pacientes ventilados o con mayor necesidad 


\begin{tabular}{|c|c|c|c|c|c|c|}
\hline Estudio (Link) & Lugar & Intervención & Control & Outcome & Resultado & Valor $\mathrm{p}$ o RR \\
\hline \multirow[t]{4}{*}{ Chen y cols. ${ }^{72}$} & \multirow{4}{*}{$\begin{array}{c}\text { China } \\
\text { Hospital of Wuhan } \\
\text { University } \\
\text { Pacientes hospitalizados }\end{array}$} & \multirow{4}{*}{$\begin{array}{l}\text { HCQ } 400 \text { mg/día x } 5 \text { días + } \\
\text { cuidado estándar } \\
(\mathrm{n}=31)\end{array}$} & \multirow{4}{*}{$\begin{array}{l}\text { Cuidado } \\
\text { estándar } \\
(n=31)\end{array}$} & Días de fiebre & HCQ 2,2 vs 3,2 control & 0,0008 \\
\hline & & & & Días de tos & HCQ 2,0 vs 3,1 control & 0,0016 \\
\hline & & & & $\begin{array}{l}\text { Cambios radiológicos día } \\
\text { 0-6 (absorción neumonía) }\end{array}$ & $\begin{array}{c}\text { HCQ } 80,6 \% \text { vs } 54,8 \% \\
\text { control }\end{array}$ & N/D \\
\hline & & & & $\begin{array}{l}\text { Progresión de la } \\
\text { enfermedad }\end{array}$ & $\begin{array}{l}\text { HCQ } 0 \% \text { vs } 12,9 \\
\text { control }\end{array}$ & N/D \\
\hline \multirow[t]{3}{*}{ Chen y cols. ${ }^{73}$} & \multirow{3}{*}{$\begin{array}{c}\text { China } \\
\text { Shanghai Public Health } \\
\text { Clinical Center } \\
\text { Pacientes hospitalizados }\end{array}$} & \multirow{3}{*}{$\begin{array}{l}\text { HCQ } 400 \text { mg/día x } 5 \text { días + } \\
\text { cuidado estándar } \\
(n=15)\end{array}$} & \multirow{3}{*}{$\begin{array}{l}\text { Cuidado } \\
\text { estándar } \\
(n=15)\end{array}$} & Cura virológica día 7 & $\begin{array}{c}\text { HCQ } 86,7 \% \text { vs } 93,3 \\
\text { control }\end{array}$ & $p>0,05$ \\
\hline & & & & Eventos adversos (diarrea) & $\begin{array}{c}\text { HCQ } 26,7 \% \text { vs } 20 \% \\
\text { control }\end{array}$ & $p>0,05$ \\
\hline & & & & Progresión radiológica & $\begin{array}{c}\text { HCQ } 33,3 \% \text { vs } 46,7 \% \\
\text { control }\end{array}$ & N/D \\
\hline \multirow[t]{3}{*}{ Tang y cols. ${ }^{74}$} & \multirow{3}{*}{$\begin{array}{c}\text { China } \\
\text { Multicéntrico } \\
\text { Pacientes hospitalizados }\end{array}$} & \multirow{3}{*}{$\begin{array}{l}\text { HCQ } 1.200 \text { mg/día por } 3 \\
\text { días, luego } 800 \text { mg/día } \\
\text { (duración total } 2 \text { o } 3 \text { se- } \\
\text { manas según severidad) + } \\
\text { cuidado estándar } \\
(\mathrm{n}=75)\end{array}$} & \multirow{3}{*}{$\begin{array}{l}\text { Cuidado } \\
\text { estándar } \\
(\mathrm{n}=75)\end{array}$} & Cura virológica día 28 & HCQ $85,4 \%$ vs $81,3 \%$ & NS \\
\hline & & & & $\begin{array}{l}\text { Mejoría de síntomas } \\
\text { día } 28\end{array}$ & $\begin{array}{c}\text { HCQ } 59,9 \% \text { vs } 66,6 \% \\
\text { control }\end{array}$ & NS \\
\hline & & & & Eventos adversos & $\begin{array}{c}\text { HCQ } 30 \% \text { vs } 8,8 \% \\
\text { control }\end{array}$ & 0,001 \\
\hline \multirow[t]{3}{*}{ Skipper y cols. ${ }^{75}$} & \multirow{3}{*}{$\begin{array}{c}\text { E.U.A./Canadá } \\
\text { Multicéntrico } \\
\text { Pacientes sintomáticos } \\
\text { confirmados adultos } \\
\text { ambulatorios }\end{array}$} & \multirow{3}{*}{$\begin{array}{c}\text { HCQ } 800 \text { mg/día x } 1 \text { vez, } \\
\text { luego } 600 \text { mg a las 6-8 } \\
\text { h y luego } 600 \mathrm{mg} / \mathrm{día} \times 4 \\
\text { d más } \\
(\mathrm{n}=212)\end{array}$} & \multirow[t]{3}{*}{$\begin{array}{l}\text { Placebo } \\
(n=211)\end{array}$} & $\begin{array}{c}\text { Cambios en una escala } \\
\text { visual de síntomas (1-10) } \\
14 \text { días }\end{array}$ & $\begin{array}{c}\text { Diferencia }-0,27 \text { puntos } \\
\text { (IC95\%, }-0,61 \text { a } 0,07 \\
\text { puntos })\end{array}$ & $p=0,117$ \\
\hline & & & & Síntomas al día 14 & $\begin{array}{l}\text { HCQ 24\% (49/201) vs } \\
30 \%(59 / 194) \text { placebo }\end{array}$ & $p=0,21$ \\
\hline & & & & Eventos adversos & $\begin{array}{l}\text { HCQ } 43 \% \text { vs } 22 \% \\
\text { placebo }\end{array}$ & $p<0,001$ \\
\hline \multirow[t]{2}{*}{ Mitjà y cols. ${ }^{70}$} & \multirow{2}{*}{$\begin{array}{c}\text { España } \\
\text { Multicéntrico } \\
\text { Pacientes ambulatorios } \\
\text { confirmados recientemente } \\
\text { (<5 días síntomas })\end{array}$} & \multirow{2}{*}{$\begin{array}{l}\text { HCQ } 800 \text { mg/día x } 1 \text { vez, } \\
\text { luego } 400 \text { mg/día } 6 \text { d + } \\
\text { cuidado estándar } \\
(n=136)\end{array}$} & \multirow[t]{2}{*}{$\begin{array}{l}\text { Cuidado } \\
\text { estándar } \\
(\mathrm{n}=157)\end{array}$} & $\begin{array}{c}\text { Reducción de carga viral } \\
\text { a } 7 \text { días } \\
\text { (Log10 copias } / \mathrm{mL} \text { ) }\end{array}$ & $\begin{array}{c}\mathrm{HCQ}-3,44 \text { vs control } \\
-3,37\end{array}$ & $\begin{array}{c}\text { Diferencia: }-0,07 \\
\text { [IC95\%: -0,44; } \\
0,29]\end{array}$ \\
\hline & & & & Riesgo de hospitalización & $\begin{array}{c}\text { HCQ } 5,9 \% \text { vs } 7,1 \% \\
\text { control }\end{array}$ & $\begin{array}{c}\text { RR } 0,75[\text { IC95\% } \\
0,32 ; 1,77]\end{array}$ \\
\hline $\begin{array}{l}\text { Boulware y } \\
\text { cols. }{ }^{69}\end{array}$ & $\begin{array}{c}\text { E.U.A./Canadá } \\
\text { Multicéntrico } \\
\text { Prevención } \\
\text { Adultos con exposición } \\
\text { ocupacional o domiciliaria } \\
\text { a caso }\end{array}$ & $\begin{array}{c}\text { Dentro de } 4 \text { días post- } \\
\text { exposición: } 800 \mathrm{mg} / \mathrm{dosis} \text {, } \\
\text { luego } 600 \mathrm{en} 6 \mathrm{a} 8 \mathrm{~h} \text { y } \\
\text { luego } 600 \mathrm{mg} / \mathrm{día} \times 4 \mathrm{~d} \\
(\mathrm{n}=414)\end{array}$ & $\begin{array}{l}\text { Dentro de } \\
4 \text { días post- } \\
\text { exposición } \\
\text { Placebo } \\
(\mathrm{n}=407)\end{array}$ & Nueva enfermedad & $\begin{array}{c}\text { HCQ } 11,8 \% \text { vs } 14,3 \% \\
\text { placebo }\end{array}$ & $\begin{array}{l}\text { Diferencia: -2,4 } \\
\text { (IC95\% -7-2,2) }\end{array}$ \\
\hline \multirow[t]{2}{*}{$\begin{array}{l}\text { Abd-Elsalam y } \\
\text { cols. }^{76}\end{array}$} & \multirow[t]{2}{*}{$\begin{array}{l}\text { Egipto } \\
\text { Tres centros }\end{array}$} & \multirow{2}{*}{$\begin{array}{l}\text { HCQ } 400 \text { mg q } 12 \text { h día } 1 \text {, } \\
\text { luego } 200 \text { mg cada } 12 \text { x } \\
15 \text { d + cuidado estándar } \\
\text { ( } \mathrm{n}=97)\end{array}$} & \multirow{2}{*}{$\begin{array}{l}\text { Cuidado } \\
\text { estándar } \\
(\mathrm{n}=197)\end{array}$} & Mortalidad & $\begin{array}{l}\text { HCQ 6/97 vs } 5 / 97 \\
\text { control }\end{array}$ & $p=0,77$ \\
\hline & & & & $\begin{array}{c}\text { Progresión a ventilación } \\
\text { mecánica }\end{array}$ & $\begin{array}{l}\text { HCQ } 4 / 97 \text { vs } 5 / 97 \\
\text { control }\end{array}$ & $p=0,75$ \\
\hline \multirow[t]{2}{*}{ Kamran y cols. ${ }^{77}$} & \multirow[t]{2}{*}{$\begin{array}{c}\text { Pakistán } \\
\text { Un solo centro }\end{array}$} & \multirow{2}{*}{$\begin{array}{l}\text { HCQ } 400 \text { mg q } 12 \text { h día } 1 \text {, } \\
\text { luego } 200 \text { mg cada } 12 x \\
4 \text { d + cuidado estándar } \\
(n=349)\end{array}$} & \multirow{2}{*}{$\begin{array}{l}\text { Cuidado } \\
\text { estándar } \\
(\mathrm{n}=151)\end{array}$} & Progresión de enfermedad & $\begin{array}{c}\text { HCQ } 3,2 \% \text { vs } 3,4 \% \\
\text { control }\end{array}$ & $p=0,865$ \\
\hline & & & & Negatividad de RPC día 14 & $\begin{array}{c}\text { HCQ } 69,9 \% \text { vs } 72,8 \% \\
\text { control }\end{array}$ & $p=0,508$ \\
\hline \multirow[t]{2}{*}{ RECOVERY ${ }^{71}$} & \multirow[t]{2}{*}{ Reino Unido } & \multirow{2}{*}{$\begin{array}{c}\text { HCQ } 800 \text { mg/dosis a hora } \\
0 \text { y } 6,12 \mathrm{~h} \text { después } 400 \\
\text { mg cada } 12 \text { h por } 9 \text { días } \\
\text { más o hasta el alta }+ \\
\text { cuidado estándar } \\
(\mathrm{n}=1.542)\end{array}$} & \multirow{2}{*}{$\begin{array}{l}\text { Cuidados } \\
\text { estándar } \\
(n=3.132)\end{array}$} & Mortalidad a 28 días & $\begin{array}{c}\text { HCQ } 26,8 \% \text { vs } 25 \% \\
\text { control }\end{array}$ & $\begin{array}{c}\text { RR } 1,09 \\
(\text { IC95\% 0,96-1,23) }\end{array}$ \\
\hline & & & & $\begin{array}{c}\text { Alta hospitalaria a los } \\
28 \text { días }\end{array}$ & $\begin{array}{c}\text { HCQ } 60,3 \% \text { vs } 62,8 \% \\
\text { control }\end{array}$ & $\begin{array}{c}\text { RR 0,92 } \\
\text { (IC95\% 0,85-0,99) }\end{array}$ \\
\hline
\end{tabular}




\begin{tabular}{|c|c|c|c|c|c|}
\hline Estudio (Link) & País/Hospital & Intervención & Control & Outcome & Resultado \\
\hline \multirow[t]{4}{*}{ Cavalcanti y cols..$^{82}$} & \multirow{4}{*}{$\begin{array}{c}\text { Brasil } \\
\text { Adultos } \\
\text { hospitalizados } \\
\text { Leve-moderado }\end{array}$} & $\begin{array}{l}\text { 1. CE }+ \text { HCQ } 400 \mathrm{mg} \\
\begin{array}{c}\mathrm{q} 12 \mathrm{~h} \text { vo } \times 7 \mathrm{~d} \\
(\mathrm{n}=221)\end{array}\end{array}$ & $\begin{array}{l}\text { Cuidados } \\
\text { estándar } \\
(\mathrm{n}=227)\end{array}$ & $\begin{array}{c}\text { Empeoramiento en una escala } \\
\text { visual de síntomas (1-7) } \\
\text { a } 15 \text { días }\end{array}$ & $\begin{array}{c}\text { HCQ vs CE: OR 1,21 (IC95\% 0,69-2,11) } \\
\text { HCQ + AZT vs CE: OR 0,99 (IC95\% 0,57-1,73) } \\
\text { HCQ + AZT vs AZT: OR 0,82 (IC95\% 0,47-1,43) }\end{array}$ \\
\hline & & \multirow{3}{*}{$\begin{array}{c}\text { 2. CE + HCQ } 400 \mathrm{mg} \\
\text { q } 12 \mathrm{~h}+\mathrm{AZT} 500 \mathrm{mg} / \\
\text { día vo } \times 7 \mathrm{~d} \\
(\mathrm{n}=217)\end{array}$} & & $\begin{array}{c}\text { Duración de la hospitalización } \\
\text { (días) }\end{array}$ & HCQ + AZT 10,3 vs HCQ 9,6 vs CE 9,5† \\
\hline & & & & $\begin{array}{l}\text { Uso de ventilación mecánica } \\
\qquad(\%)\end{array}$ & $\mathrm{HCQ}+\mathrm{AZT} 11 \%$ vs HCQ $7,5 \%$ vs CE $6,9^{\dagger}$ \\
\hline & & & & Muerte intrahospitalaria & $\mathrm{HCQ}+\mathrm{AZT} 2,9 \%$ vs HCQ $4,4 \%$ vs CE $3,5 \%^{+}$ \\
\hline
\end{tabular}

\begin{tabular}{|c|c|c|c|c|c|c|c|}
\hline Estudio (Link) & País/Hospital & $\begin{array}{c}\# \\
\text { pacientes }\end{array}$ & Intervención & Control & Outcome & Resultado & $\begin{array}{l}\text { Valor } p \text { o RR o Dif } \\
\text { porcentual }\end{array}$ \\
\hline \multirow[t]{3}{*}{ Cao y cols. ${ }^{85}$} & \multirow{3}{*}{$\begin{array}{c}\text { China } \\
\text { Jin Yin-Tan } \\
\text { Hospital, } \\
\text { Wuhan, Hubei } \\
\text { Province }\end{array}$} & \multirow[t]{3}{*}{$n=199$} & \multirow{3}{*}{$\begin{array}{l}\text { Lopinavir-ritonavir } \\
(\mathrm{LPV} / \mathrm{r})(400 / 100 \mathrm{mg}) \\
\text { cada } 12 \mathrm{~h} \text { por } 14 \\
\text { días }(\mathrm{n}=99)\end{array}$} & \multirow[t]{3}{*}{$\begin{array}{l}\text { Cuidado } \\
\text { estándar } \\
(n=100)\end{array}$} & $\begin{array}{l}\text { Tiempo para la } \\
\text { recuperación } \\
\text { clínica }\end{array}$ & $\begin{array}{c}\text { Mediana LPV/r } 16 \mathrm{~d}(13 \\
\text { a 17) vs control } 16 \mathrm{~d} \\
(15 \text { a } 18)\end{array}$ & $\begin{array}{l}\text { Hazard ratio: } 1,24 \\
(\text { IC95\%:0,90 a } 1,72)\end{array}$ \\
\hline & & & & & Mortalidad & $\begin{array}{l}\text { LPV/r } 19,2 \% \text { vs cuidado } \\
\text { estándar } 25,0 \%\end{array}$ & $\begin{array}{l}\text { Diferencia \%: -5,8 \%; } \\
\text { (IC95\%: -17,3 a 5,7) }\end{array}$ \\
\hline & & & & & Seguridad & $\begin{array}{l}\text { Gastrointestinales más } \\
\text { frecuentes en LPV/r }\end{array}$ & N/D \\
\hline RECOVERY trial ${ }^{86}$ & $\begin{array}{l}\text { E.U.A. } \\
\text { Multicéntrico }\end{array}$ & $n=11.800$ & $\begin{array}{l}\text { Lopinavir-ritonavir } \\
(\text { LPV/r) }(400 / 100 \mathrm{mg}) \\
\text { cada } 12 \mathrm{~h} \text { por } \\
14 \text { días } \\
(\mathrm{n}=1.596)\end{array}$ & $\begin{array}{l}\text { Cuidado } \\
\text { estándar } \\
(\mathrm{n}=3.376)\end{array}$ & $\begin{array}{c}\text { Mortalidad a } 28 \\
\text { días }\end{array}$ & $\begin{array}{c}22,1 \% \text { LPV/r vs cuidado } \\
\text { estándar } 21,3 \%\end{array}$ & $\begin{array}{c}\text { RR } 1,04 \\
(\text { IC95\% } 0,91-1,18) \\
p=0,58\end{array}$ \\
\hline
\end{tabular}

de oxígeno. A pesar de esta evidencia prometedora, los resultados no han sido sometidos a revisión de pares y es necesario contar con más estudios de efectividad y seguridad, sobre todo ECA, para recomendarla como una alternativa válida contra COVID-19.

Conclusión: Por lo tanto, no existe aún evidencia para recomendar su uso.

\section{Inmunoterapia}

\section{Tocilizumab}

Debido al conocimiento actual de los mecanismos involucrados en la cascada inflamatoria producida por el virus y donde interleuquina-6 (IL-6) circulante podría tener un importante rol $^{91,92}$, se ha propuesto tocilizumab (un anticuerpo monoclonal IgG1 recombinante humanizado anti receptor de IL-6) como alternativa terapéutica.

Se han publicado varios estudios observacionales que no permiten establecer la eficacia y seguridad de tocilizu- mab en COVID-1993-95. A la fecha de la construcción de este protocolo, se publicaron resultados preliminares del ensayo clínico aleatorizado COVACTA ${ }^{96}$ que comparaba tocilizumab a placebo. Tocilizumab no logró demostrar diferencias en la mejoría clínica en pacientes adultos hospitalizados con neumonía grave $(\mathrm{p}=0,36$; OR $=1,19$ IC95\% $[0,81 ; 1,76]$. Adicionalmente, no hubo diferencias significativas en el número de días sin ventilador (mediana de 22 días vs 16,5 con placebo, $\mathrm{p}=0,3202$ ), aunque sí en la duración de la hospitalización y la estadía en UCI, con una reducción de 8 días y 5,7 días, respectivamente. Respecto a seguridad, a 28 días las tasas de infecciones fueron $38,3 \%$ para tocilizumab y $40,6 \%$ placebo, y las tasas de infecciones graves fueron $21,0 \%$ y $25,9 \%$, respectivamente. Actualmente, están en marcha varios ensayos clínicos aleatorizados como REMDACTA que compara tocilizumab + remdesivir versus remdesivir ${ }^{97} \mathrm{o}$ MARIPOSA ${ }^{98}$, que estudia dos esquemas de dosificación de tocilizumab, entre otros.

Debido a que COVACTA evaluó los resultados de los 
pacientes en un día específico y los criterios de inclusión fueron amplios y parecen no estratificar según signos clínicos de hiperinflamación, el estudio podría haber pasado por alto diferencias clínicamente relevantes entre los grupos de pacientes. En el contexto de una tormenta de citoquinas inducida por COVID-19, el tratamiento anti-IL-6 podría ser más útil en una etapa temprana de la enfermedad: después del inicio de la enfermedad grave pero antes de la insuficiencia respiratoria florida. Tocilizumab continúa en evaluación bajo el estudio RECOVERY con más de 850 pacientes enrolados hasta la fecha, esto representa casi el doble de la población reclutada en COVACTA y proporcionará datos críticos para confirmar o refutar los resultados de COVACTA.

Su uso en pacientes graves con neumonía por SARSCoV-2 grave debe evaluarse caso a caso. Adicionalmente, debe recordarse que su uso está contraindicado en pacientes con: sobreinfección bacteriana, valores de AST/ALT mayores a 10 veces el límite superior de normalidad, neutrófilos menores a 500 céls $/ \mathrm{mm}^{3}$, plaquetas menores a 50.000 céls $/ \mathrm{mm}^{3}$.

- Dosis recomendada: $4-8 \mathrm{mg} / \mathrm{kg} /$ dosis por $1 \mathrm{vez}$, si no se observara mejoría (disminución de fiebre y/o PCR, podría repetirse a las $12 \mathrm{~h}$ (sin exceder los $800 \mathrm{mg}$ totales) vía endovenosa.

- Diluir en solución salina fisiológica $(\mathrm{NaCl} 9 \%$ y administrar en 1 hora (Tabla 10).
Conclusión: Hasta no tener más información, la evidencia no es suficiente para establecer una recomendación a favor o en contra de tocilizumab.

\section{Inmunoglobulina endovenosa}

No recomendada de rutina, excepto hipogamaglobulinemia o síndrome inflamatorio multisistémico.

Dosis estándar $1 \mathrm{~g} / \mathrm{kg} /$ día por 2 días o $0,3-0,5 \mathrm{~g} / \mathrm{kg} /$ día por 5 días por vía endovenosa.

\section{Plasma de convalecientes}

$\mathrm{Su}$ mecanismo de acción sería la transferencia de inmunidad pasiva (anticuerpos), en un esfuerzo por restaurar el sistema inmune durante la enfermedad crítica y la neutralización viral por supresión de la viremia.

Actualmente, la evidencia publicada sobre el uso de plasma convaleciente (PC) en pacientes con infección por SARS-CoV-2 es limitada y con un bajo nivel de evidencia ${ }^{99,100}$. Si bien, su uso en otras enfermedades infecciosas (influenza y ébola) ha tenido resultados mixtos, tres estudios aleatorizados en influenza grave no demostraron beneficios significativos ${ }^{101-103}$.

La FDA tiene regulado el PC como un producto para investigación, sugiriendo como criterios de elegibilidad para estudios clínicos, la enfermedad grave o que ponga en riesgo la vida en forma inmediata. Sin embargo, existe controversia, ya que se ha planteado que su mayor utilidad

Tabla 10. Estudios de tocilizumab

Resumen de evidencia actividad in vitro de tocilizumab

Zhang y cols. ${ }^{91} \quad$ China Revisión

Las características clínicas analizadas en estudios publicados muestran que en los pacientes con COVID-19, el recuento de linfocitos se redujo significativamente en pacientes con neumonía, especialmente aquellos con neumonía grave, mientras numerosas citoquinas (como IL-6, IL-10, IL-2 y FNT y IFN- $\gamma$ ) se incrementaron significativamente, siendo los niveles de IL-6 y otras citoquinas in vivo las principales causas de la tormenta de citoquinas

Resumen de estudios clínicos aleatorizados con tocilizumab

\begin{tabular}{|c|c|c|c|c|c|c|c|c|}
\hline Estudio (Link) & País/Hospital & Diseño & \# pacientes & Intervención & Control & Outcome & Resultado & valor $\mathbf{p}$ o RR \\
\hline \multirow[t]{7}{*}{ COVACTA Trial ${ }^{96}$} & \multirow[t]{7}{*}{ Multicéntrico } & \multirow[t]{7}{*}{ RTC, fase III } & \multirow[t]{7}{*}{$n=450$} & \multirow{7}{*}{$\begin{array}{l}\text { TCZ } 8 \text { mg/kg, } \\
\text { hasta un } \\
\text { máximo de } \\
800 \text { mg dosis }\end{array}$} & \multirow[t]{7}{*}{ Placebo } & $\begin{array}{l}\text { Mejoría status clínico } \\
\text { a } 28 \text { días, por una } \\
\text { escala de } 1 \text { a } 7\end{array}$ & $\begin{array}{c}\text { OR } 1,19 \\
(\text { IC95\% } 0,81-1,7)\end{array}$ & $p=0,36$ \\
\hline & & & & & & Mortalidad a 28 días & $\begin{array}{c}19,7 \% \text { TCZ vs place- } \\
\text { bo } 19,4 \%\end{array}$ & $p=0,941$ \\
\hline & & & & & & $\begin{array}{c}\text { Tiempo hasta el alta } \\
\text { hospitalaria }\end{array}$ & $\begin{array}{l}20 \text { días TCZ vs } 28 \\
\text { días placebo }\end{array}$ & $p=0,0370$ \\
\hline & & & & & & Duración en UCl & $\begin{array}{c}9,8 \text { días TCZ vs } 15,5 \\
\text { días placebo }\end{array}$ & $p=0,045$ \\
\hline & & & & & & Días sin ventilador & $\begin{array}{c}22 \text { días TCZ vs } 16,5 \\
\text { días placebo }\end{array}$ & $p=0,3202$ \\
\hline & & & & & & $\begin{array}{c}\text { Tasas de infecciones a } \\
28 \text { días }\end{array}$ & $\begin{array}{c}38,3 \% \text { TCZ vs } 40,6 \% \\
\text { placebo }\end{array}$ & $\mathrm{N} / \mathrm{D}$ \\
\hline & & & & & & $\begin{array}{c}\text { Tasa de infecciones } \\
\text { graves }\end{array}$ & $\begin{array}{c}21,0 \% \text { TCZ vs } 25,9 \% \\
\text { placebo }\end{array}$ & $\mathrm{N} / \mathrm{D}$ \\
\hline
\end{tabular}

IC95\% = intervalo de confianza del 95\%; N/D = no determinado; OR = odds ratio; $\mathrm{TCZ}=$ tocilizumab. 
sería en fases más precoces. Esto sería debido a que el mecanismo de acción más aceptado es la reducción de la viremia. Esto ocurre generalmente en forma natural entre los 10 y 14 días de infección, por lo que, en teoría, administrarlo en etapas precoces, cuando aún hay viremia, maximizaría en teoría su eficacia.

Existe un estudio multicéntrico aleatorizado ${ }^{104}$, que incluyó 103 pacientes con COVID-19 confirmados, con enfermedad grave o con riesgo vital; 52 pacientes recibieron PC más tratamiento estándar y 51 pacientes sólo tratamiento estándar. Este estudio no mostró una diferencia estadísticamente significativa en el tiempo de mejoría a los 28 días ni en mortalidad. Cabe destacar que este estudio fue terminado tempranamente, debido a la imposibilidad de reclutar más pacientes como consecuencia de la disminución de casos en la zona, y que la mediana de tiempo transcurrido desde el inicio de los síntomas hasta la administración de plasma fue 30 días, siendo la administración en $93 \%$ de los casos posterior al día 14 de síntomas.

Recientemente se publicó en Cochrane una revisión sistemática de $\mathrm{PC}^{105}$, la cual concluye resultados inciertos con respecto a efectividad en mortalidad o mejoría clínica.

Por lo tanto, la evidencia actual es aún de baja calidad y queda pendiente determinar la utilidad del plasma administrado en fases más tempranas.

Con respecto a la seguridad, Joyner y cols. ${ }^{106}$ reportaron 5.000 pacientes con enfermedad grave o con riesgo vital por COVID-19, enrolados en el Expanded Access
Program for COVID-19 CP Study de la Food and Drug Administration (FDA) de E.U.A., encontrando menos de $1 \%$ de eventos adversos graves durante las primeras $4 \mathrm{~h}$ de administración de PC. Se informaron 15 muertes ( $0,3 \%$ de todas las transfusiones) y sólo cuatro de ellas, se consideraron relacionadas. Esto podría indicar que el $\mathrm{PC}$ es seguro en el tratamiento de pacientes gravemente enfermos por COVID-19.

Existe una actualización de este estudio, en que se reportan datos de seguridad de 20.000 pacientes sometidos a transfusión de PC (incluidos los 5.000 previos). En este estudio el reporte de eventos adversos serios relacionados a la transfusión de PC continúa siendo menor a $1 \%$.

Conclusión: Por lo tanto, con la evidencia actual no es posible establecer una recomendación a favor o en contra del uso de PC, por falta de estudios que demuestren eficacia. Sin embargo, pareciera ser seguro. Si es usado, idealmente debiera hacerse dentro de un estudio clínico y, eventualmente, dentro de los primeros 7 a 10 días desde el inicio de los síntomas de la enfermedad.

\section{Consideraciones en el escenario de uso de terapias especificas}

Frente a la elección de alguna terapia específica, se recomienda fuertemente informar al paciente o familia tanto los potenciales beneficios como riesgos asociados, y obtener el consentimiento para su uso (Tabla 11).

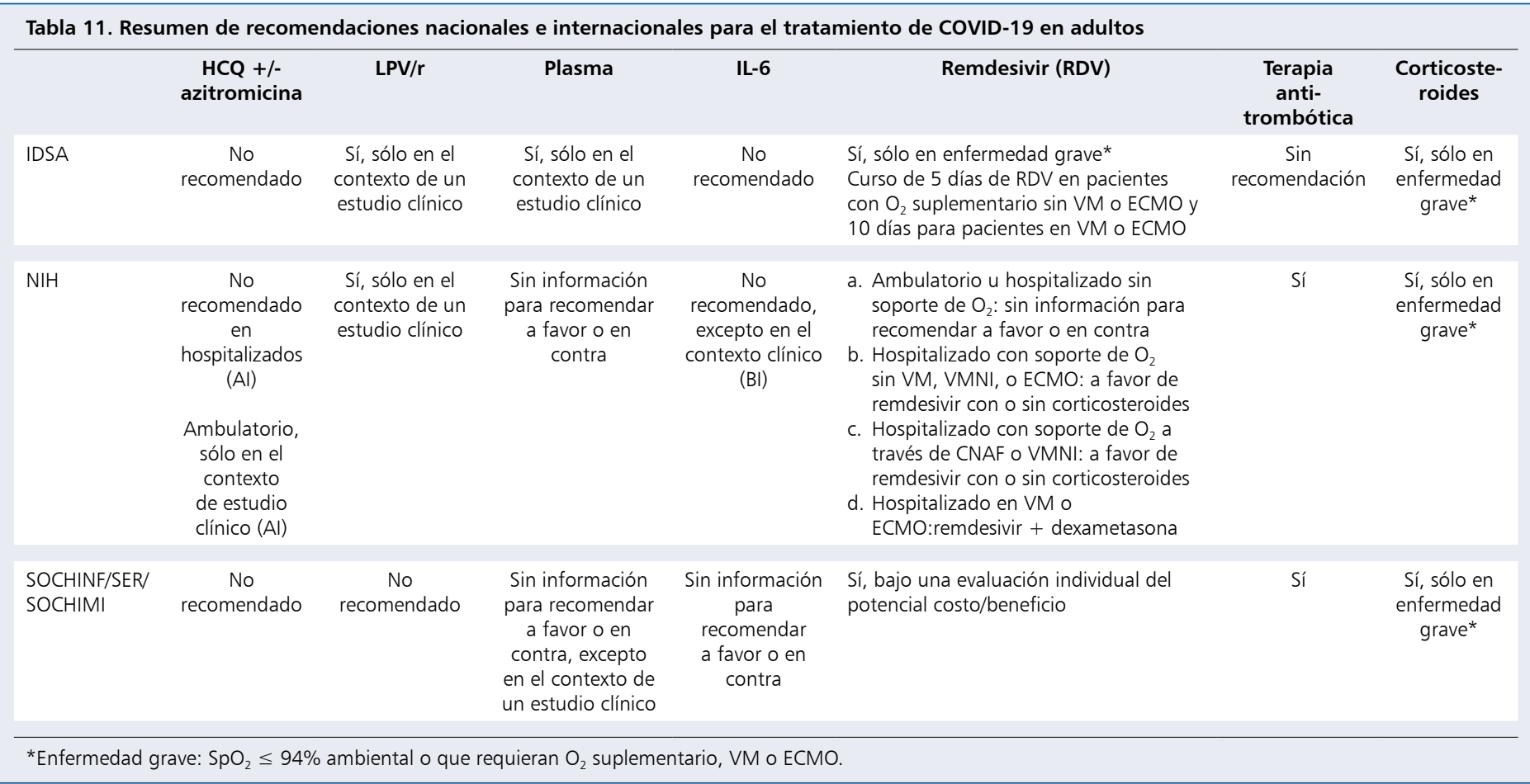




\section{Autores}

\section{Jorge Pérez Godoy}

Médico Infectólogo

Hospital Padre Hurtado, Clínica Alemana de Santiago

Facultad de medicina Clínica Alemana-Universidad del

Desarrollo

jperez@alemana.cl

\section{Ruth Rosales Chacón}

QF. Clínico

Hospital Barros Luco

ruth.rosales@redsalud.gov.cl

\section{Fernando Bernal Ortiz}

QF. Clínico

Hospital San Juan de Dios

fernando.bortiz@gmail.com

\section{Cecilia Luengo Messen}

Médico Intensivista

Unidad de Pacientes críticos Hospital Clínico Universidad de Chile

celuengomed@gmail.com

\section{José Miguel Arancibia Henríquez}

Médico Infectólogo UPC Hospital San Juan de Dios

Profesor Instructor Departamento de Medicina Interna, Universidad de Chile

jmarancibia77@gmail.com

\section{Daniela Pavez Azurmendi}

Pediatra Infectóloga

Hospital San Juan de Dios,

Clínica Alemana de Santiago

Universidad de Chile

pavezdanita@gmail.com

\section{Claudio González Muñoz}

QF. Clínico

Hospital Exequiel González Cortez

claudio.gonzalezm@redsalud.gov.cl

\section{Francisco Arancibia Hernández}

Medicina Interna, Enfermedades respiratorias Instituto Nacional del Tórax

farancibia@torax.cl

\section{Raúl Riquelme Oyarzún}

Medicina Interna, Enfermedades respiratorias

Universidad San Sebastián, sede Patagonia,

Puerto Montt

rauloriquelme@gmail.com
Regina Pérez Pérez

Pediatra Infectóloga

Departamento de Enfermedades Infecciosas e Inmunología Pediátrica, División de Pediatría

Pontificia Universidad Católica de Chile

rperezp@med.puc.cl

\section{Mirta Acuña Ávila}

Pediatra Infectóloga

Unidad de Infectología Hospital Roberto del Río

Universidad de Chile

mirta.i.acuna@gmail.com

\section{Leonardo Chanqueo Cornejo}

Médico Infectólogo

Hospital San Juan de Dios

lchanqueo@gmail.com

\section{Tomás Regueira Heskia}

Médico Intensivista

Unidad de Pacientes críticos Clínica las Condes tregueira@gmail.com

\section{Luz María Fuenzalida}

Médico Microbiólogo

Hospital Salvador, Fundación Arturo López Pérez.

luzmafuenzalida@yahoo.com

\section{Rubén Hernández Mazurek}

QF Clínico

Hospital San Borja Arriarán

rthernan@uc.cl

\section{Mariana Arias Lucero}

QF clínico

Intensivo cardiovascular Clínica Las Condes

mzarias@uc.cl

\section{Paula Impellizzeri Navarro}

QF. Clínica

Complejo asistencial Dr. Sótero del Río. Unidad de paciente Crítico pediátrico y docente Universidad Andrés Bello.

pfimpell@uc.cl

\section{Cristian Paredes Kunst}

QF clínico

Hospital La Florida

clparede@uc.cl

\section{María Eugenia Pinto Claude}

Microbióloga clínica

Hospital Clínico Universidad de Chile

mpintoc@hcuch.cl 


\section{Anexo 1. Escala CURB-65}

El CURB-65 es una escala de predicción de mortalidad utilizada en pacientes con neumonía adquirida en la comunidad. Está avalada por la British Thoracic Society.

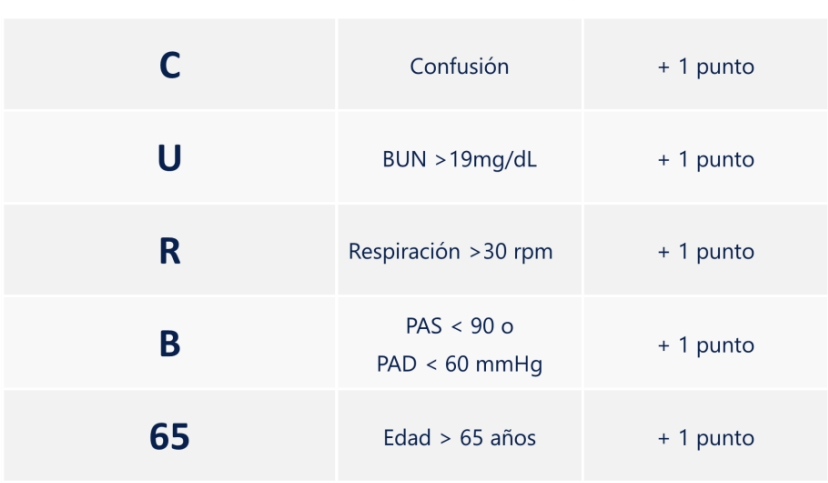

Interpretación

0-1 punto : Mortalidad de 0,2 a 2,7\%; considerar manejo ambulatorio

2-4 puntos : Mortalidad del 6,8 a 27\%; considerar hospitalización

5 puntos

Mortalidad del 57\%; considerar ingreso a UCI

\begin{tabular}{|l|}
\hline Anexo 2. Criterios de neumonía grave IDSA/ATS \\
\hline Criterios Mayores \\
- Insuficiencia respiratoria con necesidad de ventilación mecánica \\
- Shock séptico \\
\hline Criterios Menores \\
- Frecuencia respiratoria $\geq 30$ respiraciones/minuto \\
- PaO $/$ FIO $2 \leq 250$ \\
- Infiltrado multilobar \\
- Confusión/desorientación \\
- Uremia $\geq 20$ mg/dl \\
- Leucopenia $\leq 4.000$ céls/ $\mu 1$ \\
- Trombocitopenia (recuento de plaquetas $<100.000$ céls/ $\mu l)$ \\
- Hipotermia \\
- Hipotensión arterial que requiera resucitación con fluidos enérgica \\
\hline Neumonía grave: 1 criterio mayor o 3 o más criterios menores.
\end{tabular}

\section{Referencias bibliográficas}

1.- $\quad$ Zhou F, Yu T, Du R, Fan G, Liu Y, Liu Z, et al. Clinical course and risk factors for mortality of adult inpatients with COVID-19 in Wuhan, China: a retrospective cohort study. Lancet 2020; 395 (10229): 1054-62. doi:https://doi. org/10.1016/S0140-6736(20)30566-3.

2.- $\quad$ Shen K, Yang Y, Wang T, Zhao D, Jiang Y, Jin $\mathrm{R}$, et al. Diagnosis, treatment, and prevention of 2019 novel coronavirus infection in children: experts' consensus statement. World J Pediatr [Internet]. 2020; 16 (3): 223-31. Available from: http://link.springer. com/10.1007/s12519-020-00343-7 [citado el 6 de mayo de 2020].

3.- World Health Organization. Laboratory testing for coronavirus disease (COVID-19) in suspected human cases [Internet]. 2020. Available from: https://apps.who.int/iris/ handle $/ 10665 / 331329$ ?locale-attribute $=$ es \&

4.- Wang W, Xu Y, Gao R, Lu R, Han K, Wu G, et al. Detection of SARS-CoV-2 in different types of clinical specimens. JAMA [Internet]. 2020; 323 (18): 1843-4. Available from: https://jamanetwork.com/journals/jama/ fullarticle/2762997 [citado el 6 de mayo de 2020].

5.- $\quad$ Asociación Española de Pediatría de Atención Primaria. Pruebas diagnósticas de laboratorio de COVID-19 [Internet]. 2020. Available from: https://www.aepap.org/sites/default/ files/documento/archivos-adjuntos/pruebas diagnosticas_de_laboratorio_de_covid_vfinal. pdf [citado el 6 de mayo de 2020].

6.- Sociedad Española de Inmunología. Utilidad de la determinación de anticuerpos anti SARS-CoV-2 [Internet]. 2020. Available from: https://www.inmunologia.org/Upload/ Documents/1/5/2/1520.pdf [citado el 6 de mayo de 2020].

7.- $\quad$ Cheng M P, Papenburg J, Desjardins M, Kanjilal S, Quach C, Libman M, et al. Diagnostic testing for Severe Acute Respiratory Syndrome-Related Coronavirus 2. Ann Intern Med [Internet]. 2020; 172 (11): 726-34. Available from: https://www. acpjournals.org/doi/10.7326/M20-1301 [citado el 6 de mayo de 2020].

8.- $\quad$ Sociedad Chilena de Alergia e Inmunología. Respuesta inmune contra SARS-CoV-2 (COVID-19) y utilidad de las pruebas serológicas [Internet]. 2020. Available from: http://www.colegiomedico.cl/wp-content/ uploads/2020/04/Comunicado-SCAI-COVID19.-18-abril-2020.pdf [citado el 6 de mayo de 2020]

9.- Zhao J, Yuan Q, Wang H, Liu W, Liao X, Su $\mathrm{Y}$, et al. Antibody responses to SARS-CoV-2 in patients with novel coronavirus disease 2019. Clin Infect Dis [Internet]. 2020;ciaa344. Available from: https://academic.oup com/cid/advance-article/doi/10.1093/cid/ ciaa344/5812996 [citado el 6 de mayo de 2020].

10.- Pan Y, Zhang D, Yang P, Poon L L M, Wang Q. Viral load of SARS-CoV-2 in clinical samples. Lancet Infect Dis [Internet]. 2020; 20 (4): 411-2. Available from: https://linkinghub. elsevier.com/retrieve/pii/S1473309920301134 [citado el 5 de mayo de 2020].

11.- World Health Organization. Laboratory guidelines for the detection and diagnosis of COVID-19 virus infection [Internet]. 2020. Available from: https://apps.who.int/iris/ handle/10665/331329?locale-attribute $=$ es\&

12.- Zou L, Ruan F, Huang M, Liang L, Huang $\mathrm{H}$, Hong $\mathrm{Z}$, et al. SARS-CoV-2 viral load in upper respiratory specimens of infected patients. N Engl J Med [Internet]. 2020; 382 (12): 1177-9. Available from: http://www. nejm.org/doi/10.1056/NEJMc2001737 [citado el 5 de mayo de 2020].

13.- SEIMC. Recomendaciones institucionales documento de posicionamiento de la SEIMC sobre el diagnóstico microbiólogo de COVID-19. [Internet]. Available from: https:// seimc.org/contenidos/documentoscientificos/ recomendaciones/seimc-rc-2020

Posicionamiento_SEIMC diagnostico microbiologico_COVID19.pdf [citado el 5 de septiembre de 2020].

14.- SEIMC. Reflexiones de SEIMC sobre el uso de la detección de antígenos y anticuerpos para diagnóstico de COVID-19 [Internet]. Available from: https://seimc.org/contenidos/ noticias/2020/seimc-nt-2020-Reflexiones deteccion_Ag_y_AC_COVID-19.pdf [citado el 5 de septiembre de 2020].

15.- Patel R, Babady E, Theel E S, Storch G A, Pinsky B A, St. George K, et al. Report from the American Society for Microbiology COVID-19 International Summit, 23 March 2020: Value of Diagnostic Testing for SARSCoV-2/COVID-19. MBio [Internet]. 2020 11 (2). Available from: https://mbio.asm. org/content/11/2/e00722-20 [citado el 5 de septiembre de 2020]. 
16.- Loeffelholz M J, Tang Y-W. Laboratory diagnosis of emerging human coronavirus infections - the state of the art. Emerg Microbes Infect [Internet]. 2020; 9 (1): 74756. Available from: https://www.tandfonline. com/doi/full/10.1080/22221751.2020.1745095 [citado el 6 de mayo de 2020].

17.- Porte L, Legarraga P, Vollrath V, Aguilera X, Munita J M, Araos R, et al. Evaluation of novel antigen-based rapid detection test for the diagnosis of SARS-CoV-2 in respiratory samples. SSRN Electron J [Internet]. 2020; 99: 328-33. Available from: https://www.ssrn. com/abstract $=3569871$.

18.- Diao B, Wen K, Chen J, Liu Y, Yuan Z, Han C, et al. Diagnosis of Acute Respiratory Syndrome Coronavirus 2 Infection by detection of nucleocapsid protein (preprint). medRxiv [Internet]. 2020; 2020.03.07.20032524. Available from: https:// www.medrxiv.org/content/10.1101/2020.03. $07.20032524 \mathrm{v} 2$ [citado el 6 de septiembre de 2020].

19.- Li Z, Yi Y, Luo X, Xiong N, Liu Y, Li S, et al. Development and clinical application of a rapid IgM-IgG combined antibody test for SARS-CoV-2 infection diagnosis. J Med Virol [Internet]. 2020; 92 (9): 1518-24. Available from: https://onlinelibrary.wiley.com/doi/ abs/10.1002/jmv.25727 [citado el 6 de mayo de 2020].

20.- Sethuraman N, Jeremiah S S, Ryo A. Interpreting diagnostic tests for SARS-CoV-2. JAMA [Internet]. 2020; 323 (22): 2249-51. Available from: https:/jamanetwork.com/ journals/jama/fullarticle/2765837 [citado el 15 de mayo de 2020].

21.- American College of Radiology. ACR Recommendations for the use of chest radiography and computed tomography (CT) for suspected COVID-19 infection [Internet]. Available from: https://www. acr.org/Advocacy-and-Economics/ACRPosition-Statements/Recommendations-forChest-Radiography-and-CT-for-SuspectedCOVID19-Infection [citado el 6 de mayo de 2020].

22.- Metlay J P, Waterer G W, Long A C, Anzueto A, Brozek J, Crothers K, et al. diagnosis and treatment of adults with community-acquired pneumonia. An Official Clinical Practice Guideline of the American Thoracic Society and Infectious Diseases Society of America. Am J Respir Crit Care Med [Internet]. 2019; 200 (7): e45-67. Available from: https://www.atsjournals.org/ doi/10.1164/rccm.201908-1581ST [citado el 6 de mayo de 2020].

23.- Massachusetts General Hospital. COVID-19 treatment guidance [Internet]. 2020. Available from: https://www.massgeneral.org/assets/ $\mathrm{MGH} / \mathrm{pdf} /$ news/coronavirus/mass-general-
COVID-19-treatment-guidance.pdf [citado el 15 de septiembre de 2020].

24.- McCreary E K, Pogue J M. Coronavirus disease 2019 Treatment: a review of early and emerging options. Open Forum Infect Dis [Internet]. 2020; 7 (4): ofaa105. Available from: https://academic.oup.com/ofid/article/ doi/10.1093/ofid/ofaa105/5811022 [citado el 6 de mayo de 2020].

25.- Alhazzani W, Møller M H, Arabi Y M, Loeb M, Gong M N, Fan E, et al. Surviving sepsis campaign: guidelines on the management of critically ill adults with Coronavirus disease 2019 (COVID-19). Intensive Care Med [Internet]. 2020; 46 (5): 854-87. Available from: http://link.springer.com/10.1007/ s00134-020-06022-5 [citado el 6 de mayo de 2020].

26.- MINSAL. Recomendaciones clínicas basadas en evidencia coronavirus/COVID-19. [Internet]. 2020. Available from: https:// diprece.minsal.cl/temas-de-salud/temas-desalud/guias-clinicas-no-ges/guias-clinicasno-ges-enfermedades-transmisibles/covid-19/ recomendaciones/ [citado el 15 de septiembre de 2020].

27.- National Institutes of Health (NIH). Coronavirus disease 2019 (COVID-19) treatment guidelines [Internet]. Available from: https://www. covid19treatmentguidelines.nih.gov/ [citado el 15 de septiembre de 2020].

28.- CDC. Management of patients with confirmed 2019-nCoV [Internet]. Available from: https:// www.cdc.gov/coronavirus/2019-ncov/hcp/ clinical-guidance-management-patients.html [citado el 15 de septiembre de 2020].

29.- Infectious Diseases Society of America. Infectious Diseases Society of America guidelines on the treatment and management of patients with COVID-19 [Internet]. Available from: https://www.idsociety. org/practice-guideline/covid-19-guidelinetreatment-and-management/ [citado el $15 \mathrm{de}$ septiembre de 2020].

30.- Bakare L S, Allen J M. COVID-19 Therapeutics: making sense of it all. AACN Adv Crit Care [Internet]. 2020; 31 (3): 239-49. Available from: http://www.ncbi.nlm.nih.gov/ pubmed/32668460 [citado el 15 de septiembre de 2020].

31.- Wang Y, Jiang W, He Q, Wang C, Wang B, Zhou P, et al. Early, low-dose and short-term application of corticosteroid treatment in patients with severe COVID-19 pneumonia: single-center experience from Wuhan, China (preprint). medRxiv [Internet]. 2020; Available from: https://doi. org/10.1101/2020.03.06.20032342 [citado el 15 de septiembre de 2020].

32.- Horby P, Lim W S, Emberson J, Mafham M, Bell J, Linsell L, et al. Dexamethasone for COVID-19-preliminary report effect of dexamethasone in hospitalized patients with COVID-19-preliminary report (preprint). N Engl J Med [Internet]. 2020; Available from: 10.1056/NEJMoa2021436 [citado el 6 de septiembre de 2020].

33.- Sterne J A C, Murthy S, Díaz J V, Slutsky A S, Villar J, Angus D C, et al. Association between administration of systemic corticosteroids and mortality among critically ill patients with COVID-19. JAMA [Internet]. 2020; 324 (13): 1330. Available from: https://jamanetwork.com/journals/jama/ fullarticle/2770279 [citado el 15 de septiembre de 2020].

34.- Jeronimo C M P, Farías M E L, Val F F A, Sampaio V S, Alexandre M A A, Melo G C, et al. Methylprednisolone as adjunctive therapy for patients hospitalized with coronavirus disease 2019 (COVID-19; Metcovid): a randomized, double-blind, phase IIb, placebocontrolled trial. Clin Infect Dis [Internet]. 2020; Available from: https://academic.oup. com/cid/advance-article/doi/10.1093/cid/ ciaa1177/5891816 [citado el 15 de septiembre de 2020].

35.- World Health Organization. Corticosteroids for COVID-19 [Internet]. 2020. Available from: https://www.who.int/publications/i/item/ WHO-2019-nCoV-Corticosteroids-2020.1 [citado el 15 de septiembre de 2020].

36.- Klok F A, Kruip M J H A, van der Meer N J M, Arbous M S, Gommers D A M P J, Kant K M, et al. Incidence of thrombotic complications in critically ill ICU patients with COVID-19. Thromb Res 2020; 191: 1457. doi: 10.1016/j.thromres.2020.04.013.

37.- Helms J, Tacquard C, Severac F, LeonardLorant I, Ohana M, Delabranche X, et al. High risk of thrombosis in patients with severe SARS-CoV-2 infection: a multicenter prospective cohort study. Intensive Care Med [Internet]. 2020; 46 (6): 1089-98. Available from: http://link.springer.com/10.1007/ s00134-020-06062-x [citado el 15 de septiembre de 2020].

38.- Lodigiani C, Iapichino G, Carenzo L, Cecconi M, Ferrazzi P, Sebastian T, et al. Venous and arterial thromboembolic complications in COVID-19 patients admitted to an academic hospital in Milan, Italy. Thromb Res [Internet]. 2020; 191: 9-14. Available from: https://linkinghub.elsevier.com/retrieve/pii/ S0049384820301407 [citado el 6 de mayo de 2020].

39.- Leisman D E, Deutschman C S, Legrand M. Facing COVID-19 in the ICU: vascular dysfunction, thrombosis, and dysregulated inflammation. Intensive Care Med [Internet]. 2020; Available from: http://link.springer. com/10.1007/s00134-020-06059-6 [citado el 6 de mayo de 2020]. 
40.- Paranjpe I, Fuster V, Lala A, Russak A J, Glicksberg B S, Levin M A, et al. Association of Treatment dose anticoagulation with inhospital survival among hospitalized patients with COVID-19. J Am Coll Cardiol [Internet]. 2020; 76 (1): 122-4. Available from: https:// www.onlinejacc.org/content/76/1/122 [citado el 15 de septiembre de 2020].

41.- Tang N, Bai H, Chen X, Gong J, Li D, Sun $\mathrm{Z}$. Anticoagulant treatment is associated with decreased mortality in severe coronavirus disease 2019 patients with coagulopathy. $\mathrm{J}$ Thromb Haemost [Internet]. 2020; 18 (5): 1094-9. Available from: https://onlinelibrary. wiley.com/doi/abs/10.1111/jth.14817 [citado el 6 de mayo de 2020].

42.- Thachil J, Tang N, Gando S, Falanga A, Cattaneo M, Levi M, et al. ISTH interim guidance on recognition and management of coagulopathy in COVID-19. J Thromb Haemost 2020; 18 (5): 1023-6. https://doi. org/10.1111/jth. 14810

43.- Spyropoulos A C, Levy J H, Ageno W, Connors J M, Hunt B J, Iba T, et al. Scientific and standardization committee communication: clinical guidance on the diagnosis, prevention, and treatment of venous thromboembolism in hospitalized patients with COVID-19. J Thromb Haemost [Internet]. 2020; 18 (8): 1859-65. Available from: https://pubmed.ncbi.nlm.nih. gov/32459046/ [citado el 15 de septiembre de 2020].

44.- Marietta M, Ageno W, Artoni A, De Candia E, Gresele P, Marchetti M, et al. COVID-19 and haemostasis: A position paper from Italian Society on Thrombosis and Haemostasis (SISET). Blood Transfus [Internet]. 2020; 18 (3): 167-9. Available from: https://pubmed. ncbi.nlm.nih.gov/32281926/ [citado el 15 de septiembre de 2020].

45.- Barnes G D, Burnett A, Allen A, Blumenstein M, Clark N P, Cuker A, et al. Thromboembolism and anticoagulant therapy during the COVID-19 pandemic: interim clinical guidance from the anticoagulation forum. J Thromb Thrombolysis [Internet]. 2020; 50 (1): 72-81. Available from: http:// link.springer.com/10.1007/s11239-02002138-z [citado el 15 de septiembre de 2020].

46.- Connors J M, Levy J H. COVID-19 and its implications for thrombosis and anticoagulation. Blood [Internet]. 2020; 135 (23): 2033-40. Available from: https://pubmed. ncbi.nlm.nih.gov/32339221/ [citado el 15 de septiembre de 2020].

47.- Wang Y, Zhang D, Du G, Du R, Zhao J, Jin $\mathrm{Y}$, et al. Remdesivir in adults with severe COVID-19: a randomised, double-blind, placebo-controlled, multicentre trial. Lancet [Internet]. 2020 May 29 [citado el 6 de mayo de 2020];395(10236):1569-78. Available from: https://linkinghub.elsevier.com/retrieve/ pii/S0140673620310229

48.- Beigel J H, Tomashek K M, Dodd L E, Mehta A K, Zingman BS, Kalil A C, et al. Remdesivir for the treatment of COVID-19 - final report. N Engl J Med [Internet]. 2020; NEJMoa2007764. Available from: http:// www.nejm.org/doi/10.1056/NEJMoa2007764 [citado el 6 de agosto de 2020].

49.- Spinner C D, Gottlieb R L, Criner G J, Arribas López J R, Cattelan A M, Soriano Viladomiu A, et al. Effect of remdesivir vs standard care on clinical status at 11 days in patients with moderate COVID-19. JAMA [Internet]. 2020; 324 (11): 1048. Available from: https://jamanetwork.com/journals/jama/ fullarticle/2769871 [citado el 6 de septiembre de 2020].

50.- Wang M, Cao R, Zhang L, Yang X, Liu J, Xu M, et al. Remdesivir and chloroquine effectively inhibit the recently emerged novel coronavirus (2019-nCoV) in vitro. Cell Res [Internet]. 2020 Mar 4 [citado el 6 de mayo de 2020];30(3):269-71. Available from: http://www.nature.com/articles/s41422020-0282-0

51.- Sheahan T P, Sims A C, Leist S R, Schäfer A, Won J, Brown A J, et al. Comparative therapeutic efficacy of remdesivir and combination lopinavir, ritonavir, and interferon beta against MERS-CoV. Nat Commun [Internet]. 2020; 11 (1): 222. Available from: http://www.nature.com/ articles/s41467-019-13940-6 [citado el 6 de agosto de 2020].

52.- Kujawski S A, Wong K K, Collins J P, Epstein L, Killerby M E, Midgley C M, et al. Clinical and virologic characteristics of the first 12 patients with coronavirus disease 2019 (COVID-19) in the United States. Nat Med [Internet]. 2020; 26 (6): 861-8. Available from: http://www.nature.com/articles/s41591020-0877-5 [citado el 6 de agosto de 2020].

53.- Humeniuk R, Mathias A, Cao H, Osinusi A, Shen G, Chng E, et al. Safety, tolerability, and pharmacokinetics of remdesivir, an antiviral for treatment of COVID-19, in healthy subjects. Clin Transl Sci [Internet]. 2020; 13 (5): cts.12840. Available from: https:// onlinelibrary.wiley.com/doi/abs/10.1111/ cts. 12840 [citado el 6 de agosto de 2020].

54.- Goldman J D, Lye D C B, Hui D S, Marks K M, Bruno R, Montejano R, et al. Remdesivir for 5 or 10 days in patients with severe COVID-19. N Engl J Med [Internet]. 2020; NEJMoa2015301. Available from: http:// www.nejm.org/doi/10.1056/NEJMoa2015301 [citado el 6 de agosto de 2020].

55.- Grein J, Ohmagari N, Shin D, Díaz G, Asperges E, Castagna A, et al. Compassionate use of remdesivir for patients with severe COVID-19. N Engl J Med [Internet].
2020 Jun 11 [citado el 6 de mayo de 2020];382(24):2327-36. Available from: http:// www.nejm.org/doi/10.1056/NEJMoa2007016

56.- Furuta Y, Gowen B B, Takahashi K, Shiraki K, Smee D F, Barnard D L. Favipiravir (T705), a novel viral RNA polymerase inhibitor. Antiviral Res [Internet]. 2013; 100 (2): 44654. Available from: https://linkinghub.elsevier. com/retrieve/pii/S0166354213002635 [citado el 16 de agosto de 2020].

57.- Lou Y, Liu L, Qiu Y. Clinical Outcomes and Plasma concentrations of baloxavir marboxil and favipiravir in COVID-19 patients: an exploratory randomized, controlled trial (preprint). medRxiv [Internet]. 2020; 2020.04.29.20085761. Available from: https:// www.medrxiv.org/content/10.1101/2020.04.29 .20085761v1 [citado el 16 de agosto de 2020].

58.- Chen C, Zhang Y, Huang J, Yin P, Cheng $\mathrm{Z}$, Wu J, et al. Favipiravir versus arbidol for COVID-19: a randomized clinical trial (preprint). medRxiv [Internet]. 2020; Available from: https://www.medrxiv.org/con tent/10.1101/2020.03.17.20037432v1.full.pdf [citado el 16 de agosto de 2020].

59.- Ivashchenko A A, Dmitriev K A, Vostokova N V, Azarova VN, Blinow A A, Egorova A $\mathrm{N}$, et al. AVIFAVIR for treatment of patients with moderate COVID-19: interim results of a Phase II/III multicenter randomized clinical trial. Clin Infect Dis [Internet]. 2020; Available from: https://academic.oup. $\mathrm{com} / \mathrm{cid} /$ advance-article/doi/10.1093/cid/ ciaa1176/5890024 [citado el 16 de agosto de 2020].

60.- Irie K, Nakagawa A, Fujita H, Tamura R, Eto M, Ikesue $\mathrm{H}$, et al. Pharmacokinetics of favipiravir in critically ill patients with COVID-19. Clin Transl Sci [Internet]. 2020; 13 (5): cts.12827. Available from: https:// onlinelibrary.wiley.com/doi/abs/10.1111/ cts.12827 [citado el 16 de agosto de 2020].

61.- Eloy P, Solas C, Touret F, Mentré F, Malvy D, Lamballerie X, et al. Dose rationale for favipiravir use in patients infected with SARS-CoV-2. Clin Pharmacol Ther [Internet]. 2020; 108 (2): 188. Available from: https:// onlinelibrary.wiley.com/doi/abs/10.1002/ cpt.1877 [citado el 16 de agosto de 2020].

62.- Naksuk N, Lazar S, Peeraphatdit T B. Cardiac safety of off-label COVID-19 drug therapy: a review and proposed monitoring protocol. Eur Hear J Acute Cardiovasc Care [Internet]. 2020; 9 (3): 215-21. Available from: http://journals.sagepub.com/ doi/10.1177/2048872620922784 [citado el 16 de agosto de 2020].

63.- Soh M, Hifumi T, Isokawa S, Shimizu M, Otani N, Ishimatsu S. Neuroleptic malignant syndrome in patients with COVID-19. Am J Emerg Med [Internet]. 2020; Available from: https://inkinghub.elsevier.com/retrieve/pii/ 
S0735675720303843 [citado el 16 de agosto de 2020].

64.- Ben-Zvi I, Kivity S, Langevitz P, Shoenfeld Y. Hydroxychloroquine: from malaria to autoimmunity. Clin Rev Allergy Immunol [Internet]. 2012; 42 (2): 145-53. Available from: http://link.springer.com/10.1007/ s12016-010-8243-x [citado el 6 de mayo de 2020].

65.- Yao X, Ye F, Zhang M, Cui C, Huang B, Niu $P$, et al. In vitro antiviral activity and projection of optimized dosing design of hydroxychloroquine for the treatment of Severe Acute Respiratory Syndrome Coronavirus 2 (SARS-CoV-2). Clin Infect Dis [Internet]. 2020;71(15):732-9. Available from: https://academic.oup.com/cid/ article/71/15/732/5801998 [citado el 6 de mayo de 2020].

66.- Shamshirian A, Hessami A, Hadara K, Alizadeh-Navaei R, Ebrahimzadeh M A, Yip $\mathrm{G} \mathrm{W}$, et al. The role of hydroxychloroquine in the age of COVID-19: a periodic systematic review and meta-analysis (preprint). medrxiv [Internet]. 2020; Available from: https://www. medrxiv.org/content/10.1101/2020.04.14.2006 $5276 \mathrm{v} 5$ [citado el 5 de agosto de 2020].

67.- Ghazy R M, Almaghraby A, Shaaban R, Kamal A, Beshir H, Moursi A, et al. Effectiveness and safety of chloroquine or hydroxychloroquine as a mono-therapy or in combination with azithromycin in the treatment of COVID-19 patients: systematic review and meta-analysis (preprint). medRxiv [Internet]. 2020; Available from: http://medrxiv.org/content/ear ly/2020/07/28/2020.07.25.20162073.abstract [citado el 5 de agosto de 2020]

68.- Patel T K, Barvaliya M, Kevadiya B D, Patel P B, Bhalla HL. Does adding of hydroxychloroquine to the standard care provide any benefit in reducing the mortality among COVID-19 patients?: a systematic review. J Neuroimmune Pharmacol [Internet]. 2020;15(3):350-8. Available from: http://link. springer.com/10.1007/s11481-020-09930-x [citado el 5 de agosto de 2020].

69.- Boulware D R, Pullen M F, Bangdiwala A S, Pastick K A, Lofgren S M, Okafor E C, et al. A randomized trial of hydroxychloroquine as postexposure prophylaxis for COVID-19. N Engl J Med [Internet]. 2020; 383 (6): 517-25. Available from: http://www.nejm.org/ doi/10.1056/NEJMoa2016638 [citado el 5 de agosto de 2020].

70.- Mitjà $\mathrm{O}$, Corbacho-Monné M, Ubals $\mathrm{M}$, Tebe C, Peñafiel J, Tobias A, et al. Hydroxychloroquine for early treatment of adults with mild COVID-19: A randomizedcontrolled trial. Clin Infect Dis [Internet]. 2020; Available from: https://academic.oup. com/cid/advance-article/doi/10.1093/cid/ ciaa1009/5872589 [citado el 5 de agosto de 2020].

71.- Horby P, Mafham M, Linsell L, Bell J L, Staplin N, Emberson J R, et al. Effect of hydroxychloroquine in hospitalized patients with COVID-19: Preliminary results from a multi-centre, randomized, controlled trial (preprint). medRxiv [Internet]. 2020; Available from: https://doi. org/10.1101/2020.07.15.20151852 [citado el 5 de agosto de 2020].

72.- Chen Z, Hu J, Zhang Z, Jiang S, Han S, Yan $D$, et al. Efficacy of hydroxychloroquine in patients with COVID-19: results of a randomized clinical trial (preprint). medRxiv [Internet]. 2020; 7: 2020.03.22.20040758. Available from: https://www.medrxiv.org/cont ent/10.1101/2020.03.22.20040758v3 [citado el 6 de mayo de 2020].

73.- Chen J, Liu D, Liu L, Liu P, Xu Q, Xia L, et al. A pilot study of hydroxychloroquine in treatment of patients with common coronavirus disease-19 (COVID-19). J Zhejiang Univ (Med Sci) [Internet]. 2020; 49 (February): 1-10. Available from: http://www. zjujournals.com/med/EN/10.3785/j.issn.10089292.2020.03.03 [citado el 6 de mayo de 2020].

74.- $\quad$ Tang W, Cao Z, Han M, Wang Z, Chen J, Sun W, et al. Hydroxychloroquine in patients mainly with mild to moderate COVID-19: an open-label, randomized, controlled trial (preprint). medRxiv [Internet]. 2020; 2020.04.10.20060558. Available from: https:// www.medrxiv.org/content/10.1101/2020.04.10 $.20060558 \mathrm{v} 2$ [citado el 6 de mayo de 2020].

75.- Skipper C P, Pastick K A, Engen N W, Bangdiwala A S, Abassi M, Lofgren S M, et al. Hydroxychloroquine in nonhospitalized adults with early COVID-19. Ann Intern Med [Internet]. 2020; M20-4207:M20-4207. Available from: https://www.acpjournals.org/ doi/10.7326/M20-4207 [citado el 5 de agosto de 2020]

76.- Abd-Elsalam S, Esmail ES, Khalaf M, Abdo E F, Medhat M A, Abd El Ghafar M S, et al. Hydroxychloroquine in the treatment of COVID-19: a multicenter randomized controlled study. Am J Trop Med Hyg [Internet]. 2020; 103 (4): 1635-9. Available from: http://www.ajtmh.org/content/ journals/10.4269/ajtmh.20-0873 [citado el 6 de septiembre de 2020].

77.- $\quad$ Kamran S M, Mirza, Zill-e-H, Naseem A Azam R, Ullah N, Saeed F, et al. Clearing the fog: Is HCQ effective in reducing COVID-19 progression: A randomized controlled trial (preprint). medRxiv [Internet]. 2020; 2020.07.30.20165365. Available from: https:// doi.org/10.1101/2020.07.30.20165365 [citado el 6 de septiembre de 2020].

78.- Molina J M, Delaugerre C, Le Goff J,
Mela-Lima B, Ponscarme D, Goldwirt $\mathrm{L}$, et al. No evidence of rapid antiviral clearance or clinical benefit with the combination of hydroxychloroquine and azithromycin in patients with severe COVID-19 infection. Médecine Mal Infect [Internet]. 2020;50(4):384. Available from: https://linkinghub.elsevier.com/retrieve/pii/ S0399077X20300858 [citado el 6 de mayo de 2020].

79.- Dahly D, Gates S, Morris T. Statistical review of hydroxychloroquine and azithomycin as a treatment of COVID-19: results of an openlabel non-randomized clinical trial. Zenodo [Internet]. 2020;18. Available from: https:// zenodo.org/record/3724167\#.XrNjj55Kipo [citado el 6 de mayo de 2020].

80.- Rosenberg E S, Dufort E M, Udo T, Wilberschied L A, Kumar J, Tesoriero $\mathrm{J}$, et al. Association of treatment with hydroxychloroquine or azithromycin with in-hospital mortality in patients with COVID-19 in New York State. JAMA [Internet]. 2020; 323 (24): 2493. Available from: https://jamanetwork.com/journals/jama/ fullarticle/2766117 [citado el 12 de mayo de 2020].

81.- Chorin E, Dai M, Shulman E, Wadhwani L, Bar-Cohen R, Barbhaiya C, et al. The QT interval in patients with COVID-19 treated with hydroxychloroquine and azithromycin. Nat Med [Internet]. 2020; 26 (6): 808-9. Available from: http://www.nature.com/ articles/s41591-020-0888-2 [citado el 6 de agosto de 2020].

82.- Cavalcanti A B, Zampieri F G, Rosa R G, Azevedo L C P, Veiga V C, Avezum A, et al. Hydroxychloroquine with or without azithromycin in mild-to-moderate COVID-19. N Engl J Med [Internet]. 2020; NEJMoa2019014. Available from: http:// www.nejm.org/doi/10.1056/NEJMoa2019014 [citado el 5 de agosto de 2020].

83.- Yao T, Qian J, Zhu W, Wang Y, Wang G. A systematic review of lopinavir therapy for SARS coronavirus and MERS coronavirus-A possible reference for coronavirus disease-19 treatment option. J Med Virol [Internet]. 2020; 92 (6): 556-63. Available from: https:// onlinelibrary.wiley.com/doi/abs/10.1002/ jmv.25729 [citado el 6 de mayo de 2020].

84.- Chu C M. Role of lopinavir/ritonavir in the treatment of SARS: initial virological and clinical findings. Thorax [Internet]. 2004; 59 (3): 252-6. Available from: https://thorax.bmj. com/lookup/doi/10.1136/thorax.2003.012658 [citado el 6 de mayo de 2020].

85.- Cao B, Wang Y, Wen D, Liu W, Wang J, Fan $\mathrm{G}$, et al. A trial of lopinavir-ritonavir in adults hospitalized with severe COVID-19. N Engl J Med [Internet]. 2020; 382 (19): 178799. Available from: http://www.nejm.org/ 
doi/10.1056/NEJMoa2001282 [citado el 6 de mayo de 2020].

86.- University of Oxford. Statement from the chief investigators of the Randomised Evaluation of COVid-19 thERapY (RECOVERY) Trial on lopinavir-ritonavir [Internet]. 2020. Available from: www. recoverytrial.net [citado el 6 de agosto de 2020].

87.- Caly L, Druce J D, Catton M G, Jans D A, Wagstaff K M. The FDA-approved drug ivermectin inhibits the replication of SARSCoV-2 in vitro. Antiviral Res [Internet]. 2020; 178: 104787. Available from: https:// linkinghub.elsevier.com/retrieve/pii/ S0166354220302011 [citado el 19 de mayo de 2020].

88.- Momekov G, Momekova D. Ivermectin as a potential COVID-19 treatment from the pharmacokinetic point of view (preprint). medRxiv [Internet]. 2020; 2020.04.11.20061804. Available from: https:// www.medrxiv.org/content/10.1101/2020.04.11 $.20061804 \mathrm{v} 1$ [citado el 19 de mayo de 2020].

89.- Gorial F I, Mashhadani S, Sayaly H M, Dakhil B D, AlMashhadani M M, Aljabory A M, et al. Effectiveness of ivermectin as add-on therapy in COVID-19 management (Pilot Trial) (preprint). medRxiv [Internet]. 2020; 2 (December 2019): 2020.07.07.20145979. Available from: http://medrxiv.org/content/ear ly/2020/07/08/2020.07.07.20145979.abstract [citado el 6 de septiembre de 2020].

90.- Rajter J C, Sherman M S, Fatteh N, Vogel F, Sacks J, Rajter J-J. ICON (Ivermectin in COVID Nineteen) study: use of ivermectin is associated with lower mortality in hospitalized patients with COVID19 (preprint). medRxiv [Internet]. 2020; 2020.06.06.20124461. Available from: https:// doi.org/10.1101/2020.06.06.20124461 [citado el 6 de septiembre de 2020].

91.- Zhang S, Li L, Shen A, Chen Y, Qi Z. Rational Use of Tocilizumab in the treatment of novel coronavirus pneumonia. Clin Drug Investig [Internet]. 2020;40(6):511-8. Available from: http://link.springer.com/10.1007/s40261-02000917-3 [citado el 6 de mayo de 2020].

92.- Mehta P, McAuley D F, Brown M, Sánchez E, Tattersall R S, Manson J J. COVID-19: consider cytokine storm syndromes and immunosuppression. Lancet [Internet]. 2020; 395 (10229): 1033-4. Available from: https://linkinghub.elsevier.com/retrieve/pii/ S0140673620306280 [citado el 5 de agosto de 2020].
93.- Cortegiani A, Ippolito M, Greco M, Granone V, Protti A, Gregoretti C, et al. Rationale and evidence on the use of tocilizumab in COVID-19: a systematic review. Pulmonology [Internet]. 2020; Available from: https://linkinghub.elsevier.com/retrieve/ pii/S2531043720301537 [citado el 5 de septiembre de 2020].

94.- $\quad$ Lan S-H, Lai C-C, Huang H-T, Chang S-P, Lu L-C, Hsueh P-R. Tocilizumab for severe COVID-19: a systematic review and metaanalysis. Int J Antimicrob Agents [Internet] 2020; 56 (3): 106103. Available from: https://linkinghub.elsevier.com/retrieve/pii/ S0924857920302867 [citado el 5 de agosto de 2020].

95.- Rodríguez-Baño J, Pachón J, Carratalà J, Ryan P, Jarrín I, Yllescas M, et al. Treatment with tocilizumab or corticosteroids for COVID-19 patients with hyperinflammatory state: a multicentre cohort study (SAMCOVID-19). Clin Microbiol Infect [Internet]. 2020 Aug 26; Available from: https://linkinghub.elsevier.com/retrieve/ pii/S1198743X20304924 [citado el 6 de septiembre de 2020].

96.- Rosas I O, Bräu N, Waters M, Go R, Hunter B D, Bhagani S, et al. Tocilizumab in hospitalized patients with COVID-19 pneumonia (preprint). medRxiv [Internet]. 2020;2020.08.27.20183442. Available from: https://doi.org/10.1101/2020.08.27.20183442 [citado el 6 de septiembre de 2020].

97.- ClinicalTrials.gov. A study to evaluate the efficacy and safety of remdesivir plus tocilizumab compared with remdesivir plus placebo in hospitalized participants with severe COVID-19 pneumonia [Internet]. 2020. Available from: https://clinicaltrials.gov/ct2/ show/NCT04409262 [citado el 5 de agosto de 2020].

98.- ClinicalTrials.gov. A study to investigate intravenous tocilizumab in participants with moderate to severe COVID-19 pneumonia (preprint) [Internet]. 2020. Available from: https://clinicaltrials.gov/ct2/show/ NCT04363736 [citado el 5 de agosto de 2020].

99.- Liu S T H, Lin H-M, Baine I, Wajnberg A, Gumprecht J P, Rahman F, et al. Convalescent plasma treatment of severe COVID-19: A matched control study (preprint). medRxiv [Internet]. 2020;2020.05.20.20102236. Available from: https://doi. org/10.1101/2020.05.20.20102236 [citado el 15 de septiembre de 2020]

100.- Duan K, Liu B, Li C, Zhang H, Yu T, Qu J, et al. Effectiveness of convalescent plasma therapy in severe COVID-19 patients. Proc Natl Acad Sci [Internet]. 2020; 117 (17): 9490-6. Available from: http://www.pnas.org/ lookup/doi/10.1073/pnas.2004168117 [citado el 15 de septiembre de 2020].

101.- Davey R T, Fernández-Cruz E, Markowitz N, Pett S, Babiker A G, Wentworth D, et al. Anti-influenza hyperimmune intravenous immunoglobulin for adults with influenza A or B infection (FLU-IVIG): a double-blind, randomised, placebo-controlled trial. Lancet Respir Med [Internet]. 2019; 7 (11): 951-63. Available from: https://linkinghub.elsevier. com/retrieve/pii/S221326001930253X [citado el 6 de mayo de 2020].

102.- Beigel J H, Tebas P, Elie-Turenne M-C, Bajwa E, Bell T E, Cairns C B, et al. Immune plasma for the treatment of severe influenza: an openlabel, multicentre, phase 2 randomised study. Lancet Respir Med [Internet]. 2017;5(6):50011. Available from: https://linkinghub.elsevier. com/retrieve/pii/S2213260017301741 [citado el 6 de mayo de 2020].

103.- Beigel J H, Aga E, Elie-Turenne M-C, Cho J, Tebas P, Clark C L, et al. Anti-influenza immune plasma for the treatment of patients with severe influenza $\mathrm{A}$ : a randomised, double-blind, phase 3 trial. Lancet Respir Med [Internet]. 2019; 7 (11): 941-50. Available from: https://linkinghub.elsevier.com/retrieve/ pii/S2213260019301997 [citado el 6 de mayo de 2020].

104.- Li L, Zhang W, Hu Y, Tong X, Zheng S, Yang J, et al. Effect of convalescent plasma therapy on time to clinical improvement in patients with severe and life-threatening COVID-19. JAMA [Internet]. 2020; 324 (5): 460. Available from: https://jamanetwork.com/ journals/jama/fullarticle/2766943 [citado el 15 de septiembre de 2020].

105.- Piechotta V, Chai K L, Valk S J, Doree C, Monsef I, Wood E M, et al. Convalescent plasma or hyperimmune immunoglobulin for people with COVID-19: a living systematic review. Cochrane Database Syst Rev [Internet]. 2020; 2020 (7). Available from: http://doi.wiley.com/10.1002/14651858. CD013600.pub2 [citado el 15 de septiembre de 2020].

106.- Joyner M, Wright R S, Fairweather D, Senefeld J, Bruno K, Klassen S, et al. Early safety indicators of COVID-19 convalescent plasma in 5,000 patients (preprint). medRxiv [Internet]. 2020; Available from: /pmc/articles/ PMC7274247/?report=abstract [citado el 15 de septiembre de 2020]. 